\title{
Time Variation in Liquidity: The Role of Market-Maker Inventories and Revenues
}

\author{
CAROLE COMERTON-FORDE, TERRENCE HENDERSHOTT, \\ CHARLES M. JONES, PAMELA C. MOULTON, and MARK S. SEASHOLES*
}

\begin{abstract}
We show that market-maker balance sheet and income statement variables explain time variation in liquidity, suggesting liquidity-supplier financing constraints matter. Using 11 years of NYSE specialist inventory positions and trading revenues, we find that aggregate market-level and specialist firm-level spreads widen when specialists have large positions or lose money. The effects are nonlinear and most prominent when inventories are big or trading results have been particularly poor. These sensitivities are smaller after specialist firm mergers, consistent with deep pockets easing financing constraints. Finally, compared to low volatility stocks, the liquidity of high volatility stocks is more sensitive to inventories and losses.
\end{abstract}

ASSET MARKET LIQUIDITY VARIES considerably over time. This variation matters to market participants who worry about the cost of trading into or out of a desired position in a short period of time. Liquidity can affect asset prices, too. For example, investors may demand higher rates of return as compensation for holding illiquid assets and assets that are particularly sensitive to fluctuations in liquidity. However, despite the interest in aggregate liquidity from both of these angles, we know relatively little about exactly why market liquidity varies over time. Recent theoretical work by Gromb and Vayanos (2002) and Brunnermeier and Pedersen (2009), among others, postulates that limited market-maker capital can explain empirical features of asset market liquidity.

*Comerton-Forde is at University of Sydney. Hendershott is at Haas School of Business, University of California Berkeley. Jones is at Columbia Business School. Moulton is at Fordham Graduate School of Business. Seasholes is at Hong Kong University of Science and Technology. We thank the NYSE for providing data. We thank Cam Harvey, an associate editor, two anonymous referees, Yakov Amihud, Jeff Benton, Ekkehart Boehmer, Robin Greenwood, Joel Hasbrouck, Jerry Liu, Marios Panayides, Lubos̆ Pástor, Avanidhar Subrahmanyam, Dimitri Vayanos, Vish Viswanathan, Masahiro Watanabe, Pierre-Olivier Weill, and participants at the NBER Market Microstructure meeting, the Trading Frictions in Asset Markets conference at UCSB, the 2008 AFA meeting, Columbia University, the Federal Reserve Bank of New York, University of Maryland, University of Michigan, the Office of Economic Analysis of the U.S. Securities and Exchange Commission, Society of Quantitative Analysts, University of Amsterdam, University of California Santa Barbara, University of Toronto, University of Utah, and University of Washington for helpful comments. Hendershott gratefully acknowledges support from the National Science Foundation. Part of this research was conducted while Moulton was an economist and Comerton-Forde and Hendershott were visiting economists at the New York Stock Exchange. This paper combines two working papers by subsets of the authors: "Market Maker Inventories and Liquidity" and "Market Maker Revenues and Stock Market Liquidity." 
Up to now, data limitations have hampered efforts to test the broad implications of these models and demonstrate direct links between liquidity supplier behavior, capital limitations, and liquidity.

In this paper, we provide the first direct evidence that shocks to marketmaker balance sheet and income statement variables impact daily stock market liquidity. Using an 11-year (1994 to 2004) panel of daily New York Stock Exchange (NYSE) specialist inventory positions and trading revenues, we show that after specialists lose money on their inventories and/or find themselves holding large positions, effective spreads widen. Our results hold even after controlling for stock returns and volatility, and they hold at both the aggregate market level and the specialist firm level.

How are our findings consistent with the presence of market-maker financing constraints? In the short run at least, specialists and other market makers have limited capital. Lenders typically impose limits on leverage ratios (or equivalently, fix required margins). ${ }^{1}$ Information asymmetries can make it hard to raise capital quickly or cheaply. This means that market makers face short-run limits on the amount of risk they can bear. As their inventory positions grow larger (in either direction, long or short), market makers become increasingly hesitant to take on more inventory, and may quote smaller quantities at less attractive prices. Similarly, losses from trading reduce market makers' equity capital. If leverage ratios remain relatively constant, as suggested by the evidence in Adrian and Shin (2007), market makers' position limits decrease proportionately, which should similarly reduce market makers' willingness to provide liquidity.

Our general empirical approach is to predict today's liquidity (spreads) using lagged specialist inventories and trading revenues. Because of their structural advantages, specialists usually earn positive trading revenue on short-term (intraday) round-trip transactions, ${ }^{2}$ but are more exposed to the possibility of losses on inventories held for longer periods (overnight or longer). When we decompose trading revenues into intraday versus longer-horizon components, we find that revenues associated with inventories held through at least one overnight period are indeed the ones that are associated with future liquidity. This overnight breakpoint dovetails nicely with our story, because anecdotal evidence indicates that lenders and risk managers are most likely to evaluate financing terms and position limits based on daily profit and loss statements and end-of-day balance sheets.

\footnotetext{
${ }^{1}$ During our sample period, there are three distinct types of specialist firms in terms of access to capital. Specialist firms that are part of a much larger firm (such as Goldman, Fleet, Bear, or Merrill) deal with the parent in obtaining capital. Most free-standing specialist firms clear through other member firms and so deal with capital requirements imposed by these other firms. Only a few specialist firms self-clear; these firms deal directly with external lenders.

${ }^{2}$ During our sample period, an NYSE specialist generally has considerable information about liquidity supply and demand. Floor brokers routinely share information with the specialist about their trading interests. The specialist continually observes electronic orders in the limit order book. Finally, subject to NYSE rules, the specialist has a last-mover advantage in deciding whether or not to participate in a given trade.
} 
Our analysis is carried out at two levels of aggregation. We begin the paper by measuring inventories, revenues, and liquidity at the market level. However, financing constraints are likely to operate at the specialist firm level, because it is the specialist firm that must obtain capital from lenders or investors. Therefore, much of the analysis in this paper is undertaken using a panel of specialist firm inventories, revenues, and liquidity measures.

At the market level, specialist inventories and trading revenues vary considerably over time, so there is ample scope for shocks in these variables to force contractions in liquidity provision. Aggregate specialist inventories have a standard deviation of roughly $\$ 100$ million per day. We find that larger (absolute) inventory positions predict lower future liquidity. Specialists in aggregate lose money on about $10 \%$ of the trading days during our sample. The average loss is about $\$ 4$ million on these days, and losses tend to cluster together in time. We find that revenues associated with inventories held overnight forecast future liquidity. As predicted by financing constraint models, the effects of inventories and revenues on liquidity are nonlinear. Effects are greatest when inventories are highest and/or revenues are lowest.

At the specialist firm level, inventories and revenues have similarly strong effects on future liquidity. If financing constraints operate at this level, we expect to find two sets of results. First, there should be a common component in liquidity for all stocks assigned to a particular specialist firm. Second, a specialist firm's inventories and revenues should affect liquidity in its assigned stocks. Coughenour and Saad (2004) demonstrate the former; we show the latter result. As with the aggregate results, the inventory and revenue effects are greatest when a given firm's inventories are highest and/or its revenues are lowest.

To complement the time-series evidence, we next identify a set of market makers who are a priori more likely to face financial constraints. In particular, we examine specialist firms identified by Coughenour and Deli (2002) where the specialists themselves supply the equity capital. These specialist-owned firms likely face tighter financing constraints than corporate-owned specialist firms, and we show that the liquidity of stocks assigned to specialist-owned firms is more sensitive to inventories and trading losses.

During our sample period, all of the specialist-owned firms in the Coughenour and Deli (2002) sample merge with larger, corporate-owned firms. These mergers provide a potentially exogenous, positive shock to capital availability. When we follow the stocks assigned to a given specialist-owned firm, we find that liquidity in these stocks becomes somewhat less sensitive to specialist inventories and revenues after the merger. Our finding is consistent with deep pockets easing financing constraints.

We end by studying time variation of liquidity for different types of stocks. Brunnermeier and Pedersen (2009) construct a theoretical model showing that limited risk-bearing capacity can have a differential impact on high and low fundamental volatility stocks. They use the term "flight to quality" to refer to the result that the liquidity differential between high and low volatility securities is greater when market makers have taken on larger positions or when 
market-maker wealth decreases. Flight-to-quality evidence is also present in Pástor and Stambaugh (2003). We test the Brunnermeier and Pedersen (2009) predictions by examining the relation between inventories, trading revenues, and the liquidity of high and low volatility stocks. Supporting the theoretical prediction, the liquidity of high volatility stocks is more sensitive to larger inventories and losses than is the liquidity of low volatility stocks.

The remainder of the paper is organized as follows. Section I reviews related literature, and Section II provides a general description of the data. Section III shows the basic relations between aggregate market-maker inventories, revenues, and market liquidity. Section IV continues the analysis at the specialist firm level. Sections V and VI study a set of specialist-owned firms where we a priori expect financing constraints to be tighter. We conduct a cross-sectional analysis and an event study/merger analysis on these specialist-owned firms. Section VII investigates whether market makers demonstrate flight to quality in their liquidity provision, and Section VIII concludes.

\section{Related Literature}

Most models of liquidity focus on three sources of frictions: fixed costs, inventory, and asymmetric information. Kyle (1985) and Glosten and Milgrom (1985) examine the impact of private information on trading costs. Stoll (1978), Amihud and Mendelson (1980), Ho and Stoll (1981, 1983), Mildenstein and Schleef (1983), and Grossman and Miller (1988) examine the impact of inventories. Inventory models without capital constraints generally predict that liquidity (the width of the bid-ask spread) is not affected by the market maker's inventory position, but there are exceptions. For example, spreads vary positively with the amount of inventory exposure in the linear demand and supply case of Amihud and Mendelson (1980) and in Shen and Starr (2002) when a market maker faces quadratic costs. O'Hara and Oldfield (1986) show that spreads depend on inventories if market makers are risk-averse. To the extent that financing constraints can give rise to risk-averse behavior by market makers, this last model can provide an alternative backdrop for the empirical work in this paper.

Even models that do not predict a link between inventories and the width of the spread can generate time variation in liquidity, as a market maker's desire to supply liquidity is typically a function of an asset's fundamental volatility. Time variation in volatility would lead to time variation in spreads. To account for such a possibility, we control for conditional volatility in our empirical work.

Theory focusing on funding costs and financing constraints is more recent. Kyle and Xiong (2001) show that the presence of convergence traders (arbitrageurs) with decreasing risk aversion leads to correlated liquidations and high volatility. Gromb and Vayanos (2002) study a model in which arbitrageurs face margin constraints and show how arbitrageurs' liquidity provision benefits all investors. ${ }^{3}$ However, because the arbitrageurs cannot capture all of the

\footnotetext{
${ }^{3}$ Yuan (2005) provides a model that shows a link between information asymmetry and liquidity when informed investors are constrained.
} 
benefits, they fail to take the socially optimal level of risk. Weill (2007) examines dynamic liquidity provision by market makers. He shows that if market makers have access to sufficient capital they provide the socially optimal amount of liquidity, whereas if capital is insufficient or too costly then market makers undersupply liquidity. Brunnermeier and Pedersen (2009) construct a model-along the lines of Grossman and Miller (1988)— that also links market makers' funding and market liquidity. The undersupply of liquidity is more severe if market makers face predation (see Attari, Mello, and Ruckes (2005) and Brunnermeier and Pedersen (2005)).

Empirically, Chordia, Roll, and Subrahmanyam (2000), Hasbrouck and Seppi (2001), and Huberman and Halka (2001) examine the common component in liquidity changes across stocks. Coughenour and Saad (2004) show that comovement in liquidity is stronger among stocks traded by the same NYSE specialist firm. Chordia, Roll, and Subrahmanyam (2001), Chordia, Sarkar, and Subrahmanyam (2005), and Hameed, Kang, and Viswanathan (2006) find that aggregate stock market liquidity is worse following a stock market decline. We find that specialists are net long over $94 \%$ of the time, so a stock market decline is likely to reduce overall specialist capital, and this can directly explain the reduction in liquidity. Along similar lines, Mitchell, Pedersen, and Pulvino (2007) show that a loss of capital suffered by convertible and merger arbitrageurs can have strong, long-lasting effects on related asset prices.

Both liquidity supplier wealth (revenues) and the amount of capital committed by liquidity suppliers (inventories) play significant roles in the theoretical work on capital constraints and liquidity. ${ }^{4}$ Prior data on market-maker inventories and trading typically cover relatively short periods of time and/or a limited number of securities. ${ }^{5}$ While these limitations preclude testing for the relation between aggregate liquidity and limited market maker risk-bearing capacity at interday horizons, the microstructure literature has been successful in showing that inventories play an important role in intraday trading and price formation. ${ }^{6}$ For example, Madhavan and Smidt (1993), Hansch, Naik, and Viswanathan (1999), Reiss and Werner (1998), and Naik and Yadav (2003a) all find support for market makers' controlling risk by mean reverting their inventory positions toward target levels. Hansch et al. (1999) and Reiss and Werner (1998) show that differences in inventory positions across dealers determine which dealers offer the best prices and when dealers trade.

\footnotetext{
${ }^{4}$ Naik and Yadav (2003b) show that the contemporaneous relationship between government bond price changes and changes in market-maker inventories differs when market-maker inventories are very long or very short, but they do not directly examine liquidity.

${ }^{5}$ For examples using NYSE specialist data, see Hasbrouck and Sofianos (1993), Madhavan and Smidt (1993), and Madhavan and Sofianos (1998). For examples using London Stock Exchange market-maker data, see Hansch, Naik, and Viswanathan (1999), Reiss and Werner (1998), and Naik and Yadav (2003a). For futures markets data, see Manaster and Mann (1996). For options market data, see Garleanu, Pedersen, and Poteshman (2009). For foreign exchange data, see Lyons (2001) and Cao, Evans, and Lyons (2006).

${ }^{6}$ Kavajecz and Odders-White (2001) is an exception. On a trade-by-trade basis they find no evidence that specialists revise the inside quote in response to changes in inventory.
} 
Finally, a number of papers examine the profitability of specialists. ${ }^{7}$ Sofianos (1995) provides some descriptive statistics on specialist trading revenues, and Hasbrouck and Sofianos (1993) decompose specialist profits by trading horizon and find that most profits accrue from high frequency (short-term) trading strategies. Coughenour and Harris (2004) extend the results to show that the 2001 reduction in the minimum tick size impacts specialist profits. Panayides (2007) analyzes how specialists' trading, inventory, and profitability depend on their obligations under NYSE rules.

\section{Data and Descriptive Statistics}

\section{A. Data}

Data on specialist trading revenues and inventories are from the NYSE's Specialist Equity Trade Summary (SPETS). As its name suggests, SPETS provides a daily summary of specialist activity. For each stock, the file records the daily specialist purchases in dollars and shares, daily specialist sales in dollars and shares, and opening and closing specialist inventory positions. SPETS data are also employed by Madhavan and Sofianos (1998) and Hendershott and Seasholes (2007). We calculate liquidity measures using NYSE Trades and Quotes (TAQ) data, while daily stock returns come from the Center for Research in Security Prices (CRSP).

We measure economic quantities and conduct empirical work at two different levels of aggregation: the market level and the specialist firm level. Daily market-level time series start in 1994, end in 2004, and are denoted with the subscript " $m$." Analysis at the specialist firm level is conducted using an unbalanced data panel denoted with the subscript "f." The panel is unbalanced because there is substantial consolidation among specialist firms over our 11year sample period. There are 41 specialist firms in 1994, but only 7 firms at the end of our sample. ${ }^{8}$ Our analysis focuses on the 37 specialist firms that have at least 750 days of trading data (about 3 years). Each day we update the set of common stocks assigned to each specialist firm. The resulting panel incorporates $96.7 \%$ of the stock-day observations used in the aggregate (market-level) analysis.

\section{A.1. Liquidity}

What is the most appropriate measure of liquidity to use? Brunnermeier and Pedersen (2009) define market liquidity as the difference between the market-clearing transaction price and the fundamental value. Since the single Walrasian auction in their paper does not describe the actual continuous

\footnotetext{
${ }^{7}$ Market-maker profits have also been examined in other markets. For example, Hansch et al. (1999) examine how London Stock Exchange market-maker trading profits vary depending on whether the trade is preferenced or internalized.

${ }^{8}$ See Hatch and Johnson (2002) for a discussion of specialist firm consolidation. See Corwin (2004) for a discussion of the allocation of stocks to specialist firms.
} 
process of trading securities, no empirical measure of liquidity will match up perfectly with the model. However, effective spreads are designed to measure the difference between the transaction price and the fundamental value at a given time, so we use effective spread throughout the paper as our proxy for liquidity.

The effective spread is the difference between an estimate of a security's true value (the midpoint of the bid and ask quotes) and the actual transaction price. The wider the effective spread, the less liquid is the stock. We use effective spreads rather than quoted spreads because specialists and floor brokers are sometimes willing to trade at prices within quoted bid and ask prices.

Percentage effective spreads for stock $j$ at time $k$ on day $t$ are defined respectively as: ${ }^{9}$

$$
E S(\%)_{j, k, t}=2 I_{j, k, t}\left(P_{j, k, t}-M_{j, k, t}\right) / M_{j, k, t},
$$

where $I_{j, k, t}=1$ for buyer-initiated trades and $I_{j, k, t}=-1$ for seller-initiated trades, $P_{j, k, t}$ is the trade price, and $M_{j, k, t}$ is the corresponding quote midpoint. We sign trades using Lee and Ready (1991) and use quotes from 5 seconds prior to a trade for data up through 1998. After 1998, we use contemporaneous quotes to sign trades-see Bessembinder (2003). We use share volume weights to calculate a stock's daily average effective spreads $E S(\%)_{j, t}$. To calculate $E S(\%)_{m, t}$, the market-level effective spreads on date $t$, we average cross-sectionally using market capitalization weights lagged by 6 days so that recent returns are not mechanically linked to the aggregate spread measures. Specialist firm-level effective spreads $E S(\%)_{f, t}$ are calculated similarly for all common stocks assigned to that specialist firm.

Chordia et al. (2001), Jones (2006), and Hameed et al. (2006) document a downward trend in average effective spreads over much of our sample period. Figure 1 highlights the narrowing trend along with two sharp declines due to reductions in minimum tick sizes. The first reduction was from eighths to sixteenths on June 24, 1997. The second was from sixteenths to pennies on January 29, 2001. To account for these trends, we define the percentage effective spread measure $\operatorname{Spr}(\%)_{t}$ as the effective spread on day $t$ relative to its average value in the recent past (subscripts $m$ and $f$ suppressed):

$$
S p r(\%)_{t}=E S(\%)_{t}-\frac{1}{5} \sum_{j=6}^{10} E S(\%)_{t-j}
$$

Lags 6 through 10 are used because many of our specifications predict future effective spreads using specialist revenues, inventories, and returns at lags 1 through 5 as explanatory variables, and we want to ensure that the effective spread measure is not affected by contemporaneous correlation with potential right-hand side variables.

\footnotetext{
${ }^{9}$ Results for spreads measured in dollars can be found in the Internet Appendix available at http://www.afajof.org/supplements.asp.
} 


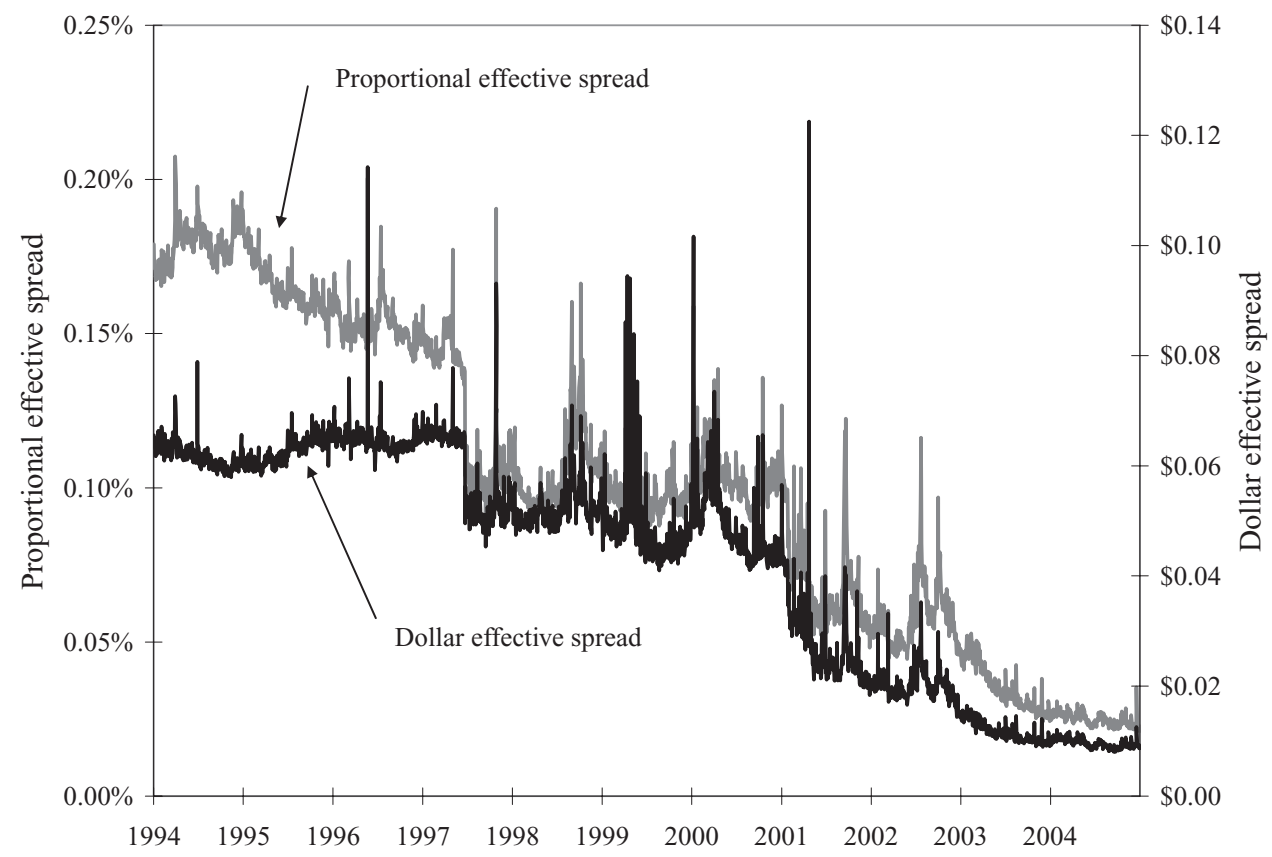

Figure 1. NYSE value-weighted dollar and percentage effective spreads, 1994 to 2004.

\section{A.2. Specialist Trading Revenues}

For each stock $i$ on each day $t$, we calculate specialist gross trading revenues as in Sofianos (1995) by marking to market the specialist's starting and ending inventories and adding the gross profits due to buying and selling during the day. ${ }^{10}$ We then decompose specialist gross trading revenues into intraday and longer-horizon components, depending on how long a position is held. The longer-horizon component, referred to as revenues from overnight inventories, are the trading revenues associated with inventories held through at least one overnight period. These are defined as the mark-to-market profit/loss on inventory held at the end of day $t-1$ plus the mark-to-market profit/loss on the net change in inventory from the end of day $t-1$ to the end of day $t$. Note that the revenues from overnight inventories depend both on the overnight stock return and on price changes during the trading day. The second (shorterhorizon) component captures intraday profits and losses and consists of the trading revenues earned on all round-trip transactions where both legs (the purchase and the sale) occur on day $t$. Please see Appendix A for details related to the decomposition of specialist revenues.

\footnotetext{
${ }^{10}$ We use the terminology of Sofianos (1995), who follows generally accepted accounting principles in referring to this daily measure as gross trading revenues. Hasbrouck and Sofianos (1993) and Coughenour and Harris (2004) refer to the same quantity as gross trading profits.
} 
Specialist revenues are aggregated each day at the market level or for each specialist firm before being demeaned. There are four regimes for demeaning, since specialist participation rates and the nature of specialist trading change markedly when the minimum tick size changes and at the beginning of $2003 .{ }^{11}$ We sometimes refer to specialist losses in the paper; because revenues are demeaned it should be understood that this refers to below-mean trading revenue, not necessarily negative specialist trading revenues.

We envisage sustained losses affecting liquidity more than a 1-day temporary loss. Therefore, our analysis sums revenues over 5-day periods. We define the gross trading revenue measure, $R e v G r_{t-1}$, the revenue from overnight inventories measure, $R e v I n v_{t-1}$, and the intraday round-trip revenue measure, $\operatorname{Rev}_{T-1}$, as the sum of the relevant daily revenue over the $[t-5, t-1]$ interval. The following equation summarizes the decomposition (subscripts $m$ and $f$ suppressed):

$$
\operatorname{Rev} G r_{t-1}=\operatorname{Rev} \operatorname{Inv}_{t-1}+\operatorname{Rev}_{T r_{t-1}}
$$

\section{A.3. Inventories}

We obtain the specialist dollar inventory $I$ for each stock $i$ at the end of day $t$. Inventories are summed cross-sectionally each day at the market level or for each specialist firm, as appropriate. Figure 2 graphs the specialists' aggregate (market-level) inventories between 1994 and 2004.

The average aggregate inventory position over the 11 years is $\$ 196$ million. Aggregate inventories have a range of $-\$ 331$ million to $+\$ 988$ million and a daily standard deviation of $\$ 137$ million. Inventory is negative only 163 of the 2,770 days in our sample, so specialists in aggregate are net long $94 \%$ of the time. Similar calculations at the specialist firm level indicate that, on average, a given specialist firm is net long $83 \%$ of the time.

To measure the amount of risk assumed by market makers, we aggregate (signed) dollar inventories up to the specialist firm level or the market level and then take the absolute value to get the magnitude of the overall position at the end of day $t-1$ (subscripts $m$ and $f$ suppressed):

$$
I n v_{t-1}=\left|\sum_{i} I_{i, t-1}\right| .
$$

\footnotetext{
${ }^{11}$ For example, specialist participation averages $8.7 \%$ during 1994 to 1996 (when prices are quoted in eighths), $13.2 \%$ during 1998 to 2000 (when prices are in sixteenths), and $15.0 \%$ during 2001 to 2002 (when the minimum tick is a penny). In early 2003, the NYSE and SEC began to investigate the trading behavior of specialists. The investigation resulted in criminal indictments of individual specialists and fines for specialist firms-see Ip and Craig (2003). Specialist participation declines to $12.5 \%$ in 2003 and $10.1 \%$ in 2004, the last year of our sample. To account for these NYSE structural changes, we specify regime changes for specialist revenues on June 24, 1997 (the adoption of sixteenths), January 29, 2001 (the adoption of decimals), and January 1, 2003. A graph of specialist participation rates over our sample period can be found in the Internet Appendix.
} 


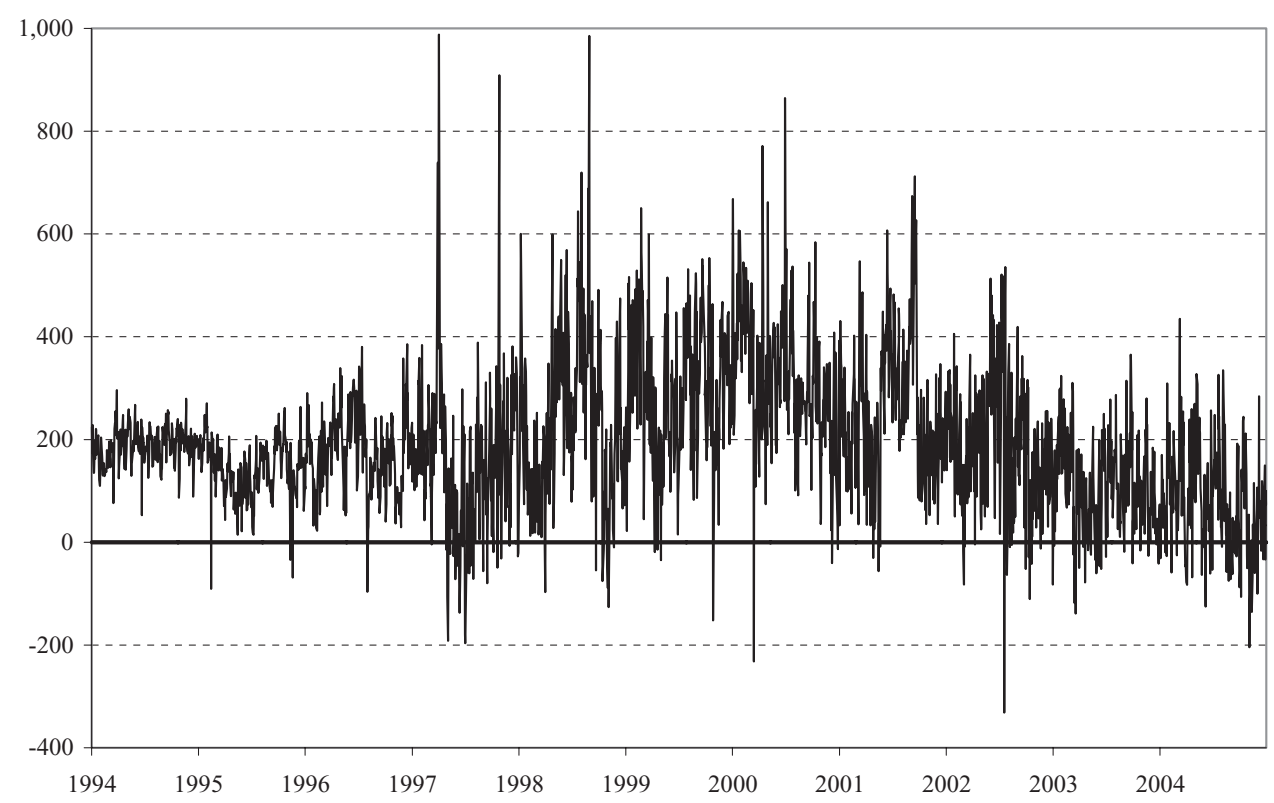

Figure 2. Aggregate specialist inventories, daily 1994 to 2004, in millions of dollars.

Dynamic models with market-maker inventories, for example, Amihud and Mendelson (1980) and Madhavan and Smidt (1993), predict that market makers mean revert their inventories towards target levels. Madhavan and Smidt (1993) find empirically that the target level is greater than zero, which we also find using our more recent sample period. Nevertheless, the amount of capital needed and the total risk borne by the specialist are proportional to the absolute inventory level, so the financing constraints story implies that we should work with the absolute value of inventories rather than deviations from target positions.

\section{A.4. Returns}

We measure the daily return of the value-weighted market portfolio of NYSE stocks, as well as the return on the valued-weighted portfolio of common stocks assigned to each specialist firm. Returns, $r_{t-1}$, are averaged over 5 days $(t-1$ to $t-5)$ and used as a predictor variable in our analysis (subscripts $m$ and $f$ suppressed):

$$
\operatorname{Ret}_{t-1}=\frac{1}{5} \sum_{j=1}^{5} r_{t-j}
$$




\section{A.5. Volatility}

To measure changes in volatility we estimate the asymmetric $\operatorname{GARCH}(1,1)$ model of Glosten, Jagannathan, and Runkle (1993). We work with $r_{t}$, the daily $\log$ value-weighted return on the market or on the portfolio of stocks assigned to a particular specialist firm (subscripts $m$ and $f$ suppressed), which is normally distributed with mean $\mu$ and conditional variance $h_{t}$ :

$$
h_{t}=\kappa+\delta h_{t-1}+\alpha u_{t-1}^{2}+\phi u_{t-1}^{2} D_{t-1},
$$

where $u_{t}=r_{t}-\mu$ is distributed $N\left(0, h_{t}\right)$, and $D_{t-1}=1$ if $u_{t-1} \geq 0$ and $D_{t-1}=0$ otherwise. In order to match the treatment of effective spreads, we define the conditional return variance measure as

$$
\operatorname{varRet} t_{t}=h_{t}-\frac{1}{5} \sum_{j=6}^{10} h_{t-j} .
$$

Many of the variables used in this paper are calculated relative to recent means over the interval $[t-10, t-6]$. This is a hybrid between working with levels and working with first differences. Pure first differences are not appropriate, since there is no theoretical reason to believe that any of the variables (liquidity, volatility, etc.) contain a unit root. Levels are not appropriate in the presence of apparent nonstationarity. While we are not aware of any econometric theory that directly addresses our approach of subtracting off recent means, such an approach is common in other areas of finance (see, e.g., the relative T-bill yield introduced by Campbell (1991) and now common in the return predictability literature). The hybrid approach induces a modest amount of moving average behavior, which requires the use of autocorrelation-consistent standard errors throughout the paper.

\section{B. Descriptive Statistics}

Table I contains correlations and standard deviations for the market-wide variables used in this paper. Aggregate specialist revenues $\left(R e v G r_{m, t-1}\right)$ are fairly volatile, with a standard deviation of $\$ 16.1$ million around the regime means. Note that all revenue variables are aggregated over 5 trading days, so the standard deviations essentially refer to weekly trading revenues. Revenues from intraday round-trips $\left(\operatorname{Rev} \mathrm{r}_{m, t-1}\right)$ are more volatile than revenues from overnight inventory $\left(\operatorname{Rev} \operatorname{Inv} v_{m, t-1}\right)$, with respective daily standard deviations of $\$ 13.9$ million and $\$ 7.7$ million. As a result, the 0.88 contemporaneous correlation between $\operatorname{Rev} r_{m, t-1}$ and $\operatorname{Rev} G r_{m, t-1}$ is much higher than the

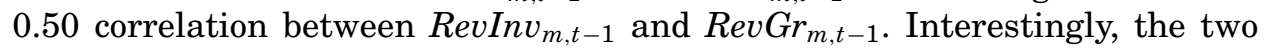
components of specialist revenues are virtually uncorrelated with each other $(\rho=0.03)$, while revenues from overnight inventory are strongly correlated with contemporaneous stock market returns $(\rho=0.59)$. The latter correlation makes sense given our earlier observation that aggregate specialist inventories are almost always net long. 


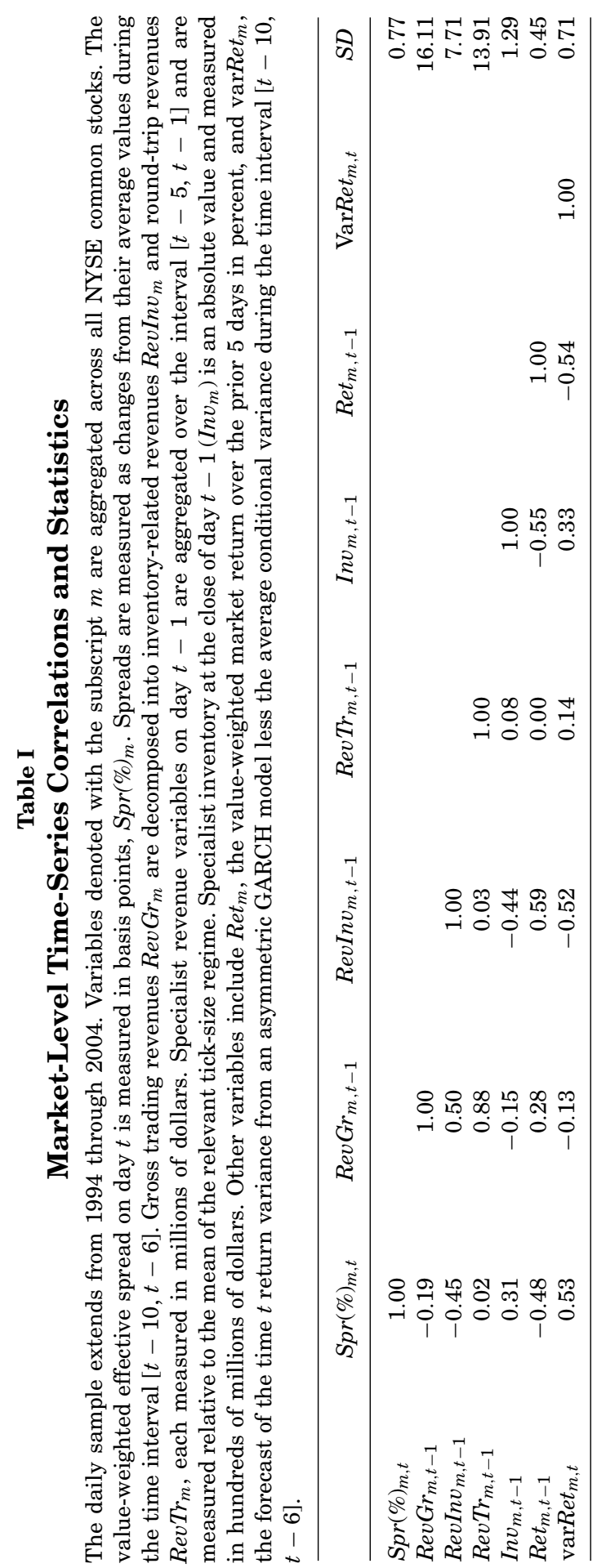


Given that we are using absolute values of inventories and specialist trading revenues as proxies for financing constraints, we expect the two measures to be negatively related. This is indeed the case, especially for revenues from overnight inventory positions. While the correlation between inventories and $R e v G r_{m, t-1}$ or $\operatorname{Rev}{ }_{m, t-1}$ are a modest -0.15 or 0.08 , respectively, the correlation of inventories with RevInv $v_{m, t-1}$ is a much stronger -0.44 . The latter correlation is a function of the average long specialist position combined with the specialist's liquidity provision role. Specialists tend to find themselves with even bigger long positions when the market declines (the contemporaneous correlation between ending inventories on day $t-1$ and the 5-day market return ending on day $t-1$ is -0.55 ), and they lose money in the process.

\section{Market-Level Liquidity}

The main empirical goal of the paper is to test whether economic state variables related to financing constraints can account for the observed time-series variation in stock market liquidity. Our main innovation is to use specialist revenues and specialist inventories as proxies for the financial constraints faced by intermediaries. Control variables account for other possible mechanisms, such as the standard theoretical link between conditional volatility and market liquidity that is present in most microstructure models.

We start by simply regressing market-wide effective spreads on day $t$ on aggregate gross trading revenues summed over the interval $[t-5, t-1]$. The results are in the first column of Table II. The coefficient on $R e v G r_{m, t-1}$ is only marginally different from zero. At first glance, this result would seem to provide little support for a financing constraints story, because it is aggregate losses that should weaken a market maker's capital position and make it more difficult to finance trading positions. However, specification (2) in the same table reveals that when gross trading revenues are decomposed into revenues associated with overnight inventory (RevInv $\left.v_{m, t-1}\right)$ and revenues associated with intraday round-trips $\left(R e v \operatorname{Tr}_{m, t-1}\right)$, inventory revenues have a large negative effect on spreads, while the coefficient on round-trip revenues is indistinguishable from zero.

Throughout the paper, we focus on revenues associated with overnight inventories because there are confounding effects between intraday trading revenues and future spreads. The variable RevTr is essentially the total dollar amount of effective spread earned on intraday round-trips by specialists less the associated losses to informed traders. Thus, it is a realized or net spread for specialists. If realized spreads are persistent for whatever reason (say, e.g., that the specialist has market power or the amount of intraday specialist trading is persistent), then the relationship between today's RevTr and tomorrow's spread could be fairly mechanical. If RevTr and spreads both increase today, they are likely to both remain high tomorrow, and a higher RevTr today ends up predicting a higher effective spread tomorrow.

In contrast, inventory-related revenues are not mechanically tied to spreads in this way. For this reason, results involving inventory-related revenues are 


\section{Table II}

\section{Aggregate Specialist Inventories and Revenues and Future Market Liquidity}

Time-series regressions on daily data from 1994 to 2004 . The dependent variable is $\operatorname{Spr}(\%)_{m, t}$, the value-weighted effective spread on day $t$ relative to its average value during the interval $[t-10$, $t-6]$, measured in basis points. Inv $H i_{m}$ is the interaction of $I n v_{m}$ and a dummy variable that is equal to 1 if $I n v_{m}$ is above the $75^{\text {th }}$ percentile of its distribution and 0 otherwise. RevInv $L o_{m}$ is the interaction of RevInv $v_{m}$ with a dummy variable equal to 1 if RevInv $v_{m}$ is below the $25^{\text {th }}$ percentile of its distribution and 0 otherwise. $\operatorname{Rev} \operatorname{Tr} L o_{m}$ is the interaction of $\operatorname{Rev} \mathrm{Tr}_{m}$ with a dummy variable equal to 1 if $\operatorname{Rev}_{T} r_{m}$ is below the $25^{\text {th }}$ percentile of its distribution and 0 otherwise. Other variables are defined in Table I. All coefficients are multiplied by $10^{3} . t$-statistics are in brackets and are based on Newey-West standard errors with 10 lags.

\begin{tabular}{|c|c|c|c|c|c|c|c|}
\hline & (1) & (2) & (3) & (4) & (5) & (6) & (7) \\
\hline Intercept & $\begin{array}{r}-42.44 \\
{[1.51]}\end{array}$ & $\begin{array}{r}-43.17 \\
{[1.74]}\end{array}$ & $\begin{array}{r}-46.83 \\
{[1.87]}\end{array}$ & $\begin{array}{r}-419.80 \\
{[7.70]}\end{array}$ & $\begin{array}{r}-303.13 \\
{[6.36]}\end{array}$ & $\begin{array}{r}-63.21 \\
\quad[1.50]\end{array}$ & $\begin{array}{r}-34.07 \\
{[0.83]}\end{array}$ \\
\hline $\operatorname{Rev} G r_{m, t-1}$ & $\begin{array}{c}-9.27 \\
{[1.88]}\end{array}$ & & & & & & \\
\hline $\operatorname{RevInv_{m,t-1}}$ & & $\begin{array}{r}-44.94 \\
{[8.37]}\end{array}$ & $\begin{array}{r}-44.85 \\
{[8.38]}\end{array}$ & & & $\begin{array}{r}-14.16 \\
{[2.95]}\end{array}$ & $\begin{array}{r}-12.93 \\
{[2.69]}\end{array}$ \\
\hline $\operatorname{RevInv} L \mathrm{Lo}_{m, t-1}$ & & & $\begin{array}{r}-22.85 \\
{[1.60]}\end{array}$ & & & & $\begin{array}{r}-29.48 \\
{[2.38]}\end{array}$ \\
\hline $\operatorname{RevTr}_{m, t-1}$ & & $\begin{array}{c}2.09 \\
{[0.67]}\end{array}$ & $\begin{array}{c}2.15 \\
{[0.71]}\end{array}$ & & & $\begin{array}{c}-1.27 \\
{[0.68]}\end{array}$ & $\begin{array}{r}-1.39 \\
{[0.77]}\end{array}$ \\
\hline $\operatorname{Rev} \operatorname{Tr} L o_{m, t-1}$ & & & $\begin{array}{c}-2.99 \\
{[1.27]}\end{array}$ & & & & $\begin{array}{c}-1.78 \\
{[0.92]}\end{array}$ \\
\hline $\operatorname{In} v_{m, t-1}$ & & & & $\begin{array}{r}187.51 \\
{[6.32]}\end{array}$ & $\begin{array}{c}85.06 \\
{[3.16]}\end{array}$ & $\begin{array}{l}18.60 \\
{[0.97]}\end{array}$ & $\begin{array}{r}-12.14 \\
{[0.56]}\end{array}$ \\
\hline $\operatorname{Inv} \_H i_{m, t-1}$ & & & & & $\begin{array}{r}104.59 \\
{[5.41]}\end{array}$ & & $\begin{array}{l}33.06 \\
{[2.18]}\end{array}$ \\
\hline $\operatorname{Ret}_{m, t-1}$ & & & & & & $\begin{array}{r}-331.18 \\
{[4.52]}\end{array}$ & $\begin{array}{r}-322.62 \\
{[4.44]}\end{array}$ \\
\hline $\operatorname{varRet}_{m, t}$ & & & & & & $\begin{array}{r}376.79 \\
{[6.02]}\end{array}$ & $\begin{array}{r}385.69 \\
{[6.34]}\end{array}$ \\
\hline Observations & 2,760 & 2,760 & 2,760 & 2,760 & 2,760 & 2,760 & 2,760 \\
\hline$R^{2}$ & 0.037 & 0.201 & 0.206 & 0.097 & 0.116 & 0.345 & 0.356 \\
\hline
\end{tabular}

easy to interpret. When specialists make money on their inventories, marketwide spreads tend to be narrow in the next period. The statistical evidence is compelling, as revenues alone explain about $20 \%$ of the daily variance in the proportional effective spread measure. In terms of economic magnitude, specification (2) in Table II shows that if inventory-related revenues are one standard deviation greater (equal to $\$ 7.7$ million from Table I), the aggregate effective spread measure is $7.7 *-44.94 / 1,000=0.35$ basis points narrower on average the next day. This amount is a little less than half of the daily standard deviation of 0.77 basis points from Table I for the spread measure itself.

Financial constraints are generally nonlinear, so we next look at whether liquidity is more sensitive to extreme specialist losses. In specification (3) we

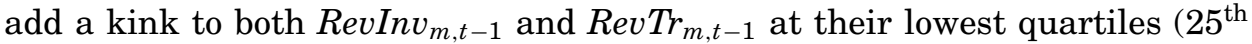
percentile). Consistent with theory, large losses are associated with wider 
spreads, and the nonlinearity is fairly pronounced. Based on the numbers in Table II, the slope coefficient on $\operatorname{RevInv}_{m, t-1}$ is about -44.85 for the majority of days and $-69.70(=-44.85-22.85)$ in the lowest quartile of the inventory revenues distribution.

Turning to our balance sheet proxy, we next test the spread-inventory relationship. Specification (4) includes only a constant and the absolute value of aggregate specialist inventories (in hundreds of millions of dollars) as right-hand side variables. We find that large inventories yesterday imply wide spreads today: An additional $\$ 100$ million in inventory, which is slightly less than a one-standard deviation change, corresponds to an increase of 0.187 basis points in our proportional effective spread measure. In specification (5), we add a kink to the linear relation between inventories and future liquidity, located at the upper quartile ( $75^{\text {th }}$ percentile) of the absolute inventory distribution. The idea is that when inventories are particularly large in either direction, market makers may be more constrained and require more compensation to provide liquidity. The data reveal strong evidence of this kind of nonlinearity. On typical days, each additional $\$ 100$ million in aggregate inventories implies a next-day market-wide effective spread that is 0.085 basis points wider. But when inventories are beyond the $75^{\text {th }}$ percentile, the sensitivity of spreads to inventories more than doubles.

In addition to our market-maker state variables, there are other variables that have been theoretically and empirically associated with changes in liquidity. For example, classic microstructure models, such as Kyle (1985) and Glosten and Milgrom (1985), conclude that liquidity should be decreasing in the variance of fundamentals. On the empirical side, Chordia et al. (2000, 2001) show that when markets fall, liquidity dries up. Perhaps our revenue and inventory variables are simply collinear with these other, previously identified effects. For example, since specialists are net long over $94 \%$ of the time, we know that profits on overnight inventory positions will be quite correlated with market returns (Table I shows that the correlation between the two is 0.59). Similarly, the specialist's obligation to buffer order flow suggests that inventories are likely to grow large following a sharp market decline (the Table I correlation between absolute inventories and returns is -0.55). While financing constraints plus average net long inventory positions together imply a correlation between market returns and next period's average liquidity, a financing constraint explanation is even more plausible if markets become illiquid when specialists lose money or take on large positions without big market moves.

Specification (6) of Table II combines specialist revenue variables, absolute inventories, market returns, and the conditional return variance in the following regression:

$$
\begin{aligned}
\operatorname{Spr}_{m, t}= & \alpha+\beta_{1} \operatorname{RevInv}_{m, t-1}+\beta_{2} \operatorname{Rev}_{\operatorname{Tr}_{m, t-1}+\beta_{3} \operatorname{Inv}_{m, t-1}} \\
& +\beta_{4} \operatorname{Ret}_{m, t-1}+\beta_{5} \operatorname{var} \operatorname{Ret}_{m, t}+\varepsilon_{m, t} .
\end{aligned}
$$

As noted above, there is a fair bit of collinearity between the various explanatory variables, so not all of the right-hand side variables remain significant. 
However, we find that the coefficient on revenues from overnight inventory $\operatorname{RevInv}_{m, t-1}$ remains negative and strongly statistically significant. When specialists lose money overall, spreads are wider than average, even if the market is not falling at the same time. ${ }^{12}$

In the final specification of Table II, we allow a nonlinear effect for both revenues and inventories. While specification (7) asks a lot of the data (given the collinearity between most of the explanatory variables), we continue to find evidence that the predictability is greatest when specialists take on large positions and when they suffer the biggest losses on their overnight inventory positions.

For robustness, we also confirm that our quasi-differencing is not driving the results. We estimate a daily vector autoregression with five lags on spreads, market returns, absolute market returns, intraday and overnight specialist revenues, and specialist inventories, taking a piecewise linear time trend out of the spreads for each tick regime. We get similar results on the importance of specialist inventories and revenues; the results are available in the Internet Appendix. ${ }^{13}$

The aggregate evidence strongly supports a role for financial constraints in shaping stock market liquidity. However, financial constraints should operate at the level of the financial intermediary. Therefore, we turn next to more disaggregated data to test whether they too support a capital constraint story.

\section{Liquidity at the Specialist Firm Level}

If specialists are marginal liquidity suppliers, then a stock's liquidity should suffer if its specialist firm faces financing constraints. In particular, if specialist firm revenues are imperfectly correlated cross-sectionally, different specialist firms may face financing constraints at different times, and we might obtain greater statistical power by conducting the analysis at the specialist firm level. At the end of our sample, there are only seven specialist firms, each with a broadly diversified list of assigned stocks. Facing little idiosyncratic risk, these specialist firms are likely to generate revenues and take on inventories that are highly correlated with each other. However, at the beginning of the sample there are 41 specialist firms and considerable cross-sectional dispersion in revenues and inventories. This dispersion aids identification.

We work with specialist firms rather than individual specialists because Coughenour and Saad (2004) find evidence that capital is allocated at the firm level. They conclude that "information about inventory and profits is shared and that firm capital constraints and other characteristics can affect the provision of liquidity" (p. 43). In conversations with us, the former head of a large specialist

\footnotetext{
${ }^{12}$ An examination of dollar spreads shows that this result is not due to a mechanical relationship between proportional spreads and the stock price level when spreads are limited by a discrete price grid. Results for spreads measured in dollars can be found in the Internet Appendix available at http://www.afajof.org/supplements.asp.

${ }^{13}$ An Internet Appendix for this article is online in the "Supplements and Datasets" section at http://www.afajof.org/supplements.asp.
} 
firm agreed with that assessment. He noted that if firm-wide inventories got too large, for example, his specialist firm risk managers would tell every specialist to widen the quote, step back for a while (reduce liquidity provision), and then begin to reduce positions. ${ }^{14}$ Internal risk managers would typically step in well short of approaching any external constraint.

To proceed, we create an unbalanced panel of specialist firm-level data with one daily observation for each specialist firm. We quasi-difference and demean all variables as discussed in Section II. In particular, we calculate gross trading revenues for each specialist firm $f$ ending on day $t\left(\operatorname{Rev} G r_{f, t}\right)$, which is then decomposed into overnight inventory-related revenues $\left(R e v I n v_{f, t}\right)$ and intraday round-trip revenues $\left(\operatorname{Rev} \operatorname{Tr}_{f, t}\right)$. We calculate the absolute dollar inventory position $\left(\operatorname{In} v_{f, t}\right)$ for each specialist firm based on its assigned stocks each day. The value-weighted effective spread measure $\left.\operatorname{Spr}(\%)_{f, t}\right)$ is calculated each day for the portfolio of stocks assigned to each specialist firm. We also calculate the value-weighted return $\left(\operatorname{Ret}_{f, t}\right)$ on the portfolio of assigned stocks in excess of the aggregate market return, along with the associated conditional volatility $\left(\right.$ varRet $_{f, t}$ ) using an asymmetric GARCH model.

Table III shows average within-firm correlations and standard deviations for the specialist-firm panel. The general correlation patterns from the marketlevel analysis in Table I carry over to the specialist firm level. Note that correlation magnitudes are generally smaller when using specialist firm-level data. Specialist firm gross trading revenues $\left(\operatorname{Rev} G r_{f, t-1}\right)$ have a standard deviation of $\$ 1.20$ million around the regime means. Again, weekly revenues from intraday round-trips $\left(\operatorname{Rev}_{T r_{f, t-1}}\right)$ are substantially more volatile $(\sigma=\$ 1.03$ million $)$ than revenues from overnight inventory $\left(\operatorname{RevInv}_{f, t-1}\right)$, with a standard deviation of $\$ 0.52$ million. The two components of specialist firm revenue are somewhat negatively correlated with each other $(\rho=-0.10)$. The correlation between $\operatorname{RevInv}_{f, t-1}$ and contemporaneous stock market returns $\operatorname{Ret}_{f, t-1}(\rho=0.31)$ is more modest than at the market level.

There is substantial heterogeneity across specialist firms. Differences include firm size, organizational structure, and types of stocks assigned. Thus, we expect considerable cross-sectional heterogeneity in regression coefficients on inventory and revenue variables. For example, a $\$ 1$ million trading loss could be a significant event for a small specialist firm, but not at all unusual for a large specialist firm. To handle this heterogeneity, we estimate a separate time-series regression for each specialist firm (see Table IV). ${ }^{15}$ We report

\footnotetext{
${ }^{14}$ Interestingly, at high frequencies (trade by trade), Naik and Yadav (2003a) find that stock-level inventories help predict a London Stock Exchange dealer's quote placing behavior, but firm-wide inventories do not. At high frequencies, dealers may not be instantaneously aware of changes in firm-wide state variables and may only be able to condition on own-stock variables.

${ }^{15}$ Because the tick size changes affect liquidity as may the consolidation of specialist firms, we actually estimate the regressions separately for each "specialist-firm regime." Specifically, each time a specialist firm merges or the tick size changes, a new specialist-firm regime begins. We require at least 100 observations for each specialist-firm regime, although the results are not sensitive to this requirement.
} 


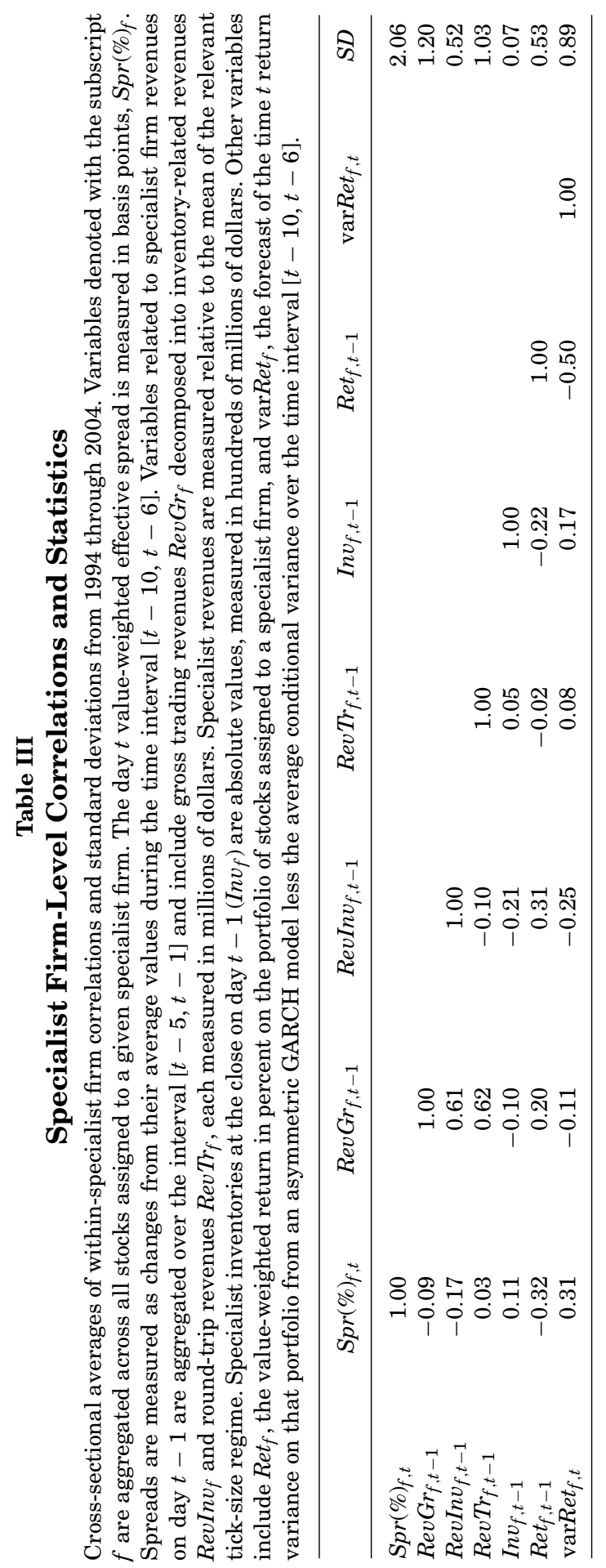




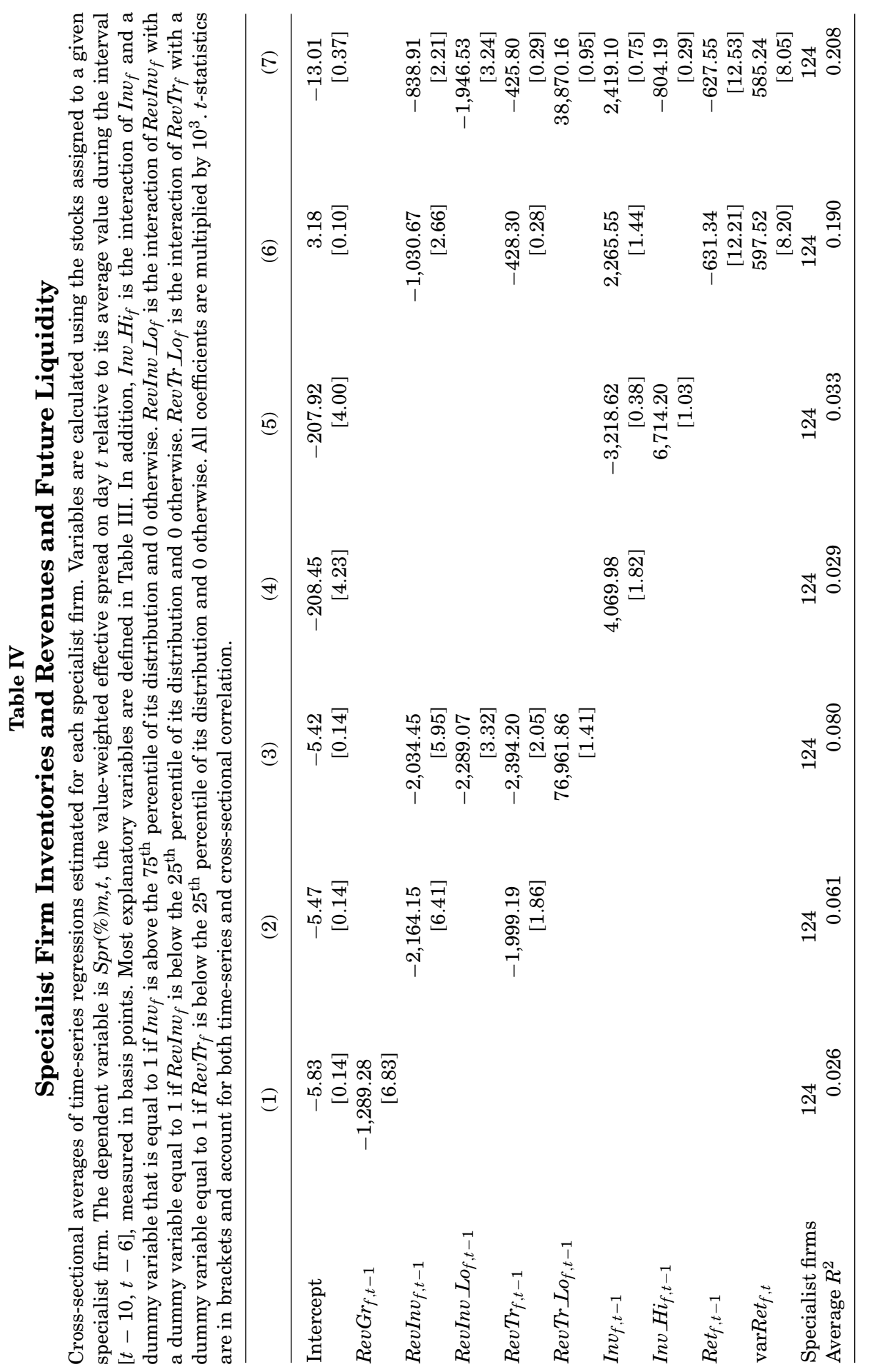


cross-sectional average coefficients, and standard errors account for both crosssectional correlation across specialist firms and time-series persistence within specialist firms (see Appendix B for details).

Specification (1) shows that, in contrast to earlier regressions at the aggregate level, specialist firm gross trading revenues are significant predictors of next-day liquidity in that firm's assigned stocks. As discussed earlier, there could be confounding effects between intraday revenues $\left(\operatorname{Rev}_{T} r_{f, t-1}\right)$ and future spreads, so we again decompose the specialist firm's daily gross revenues

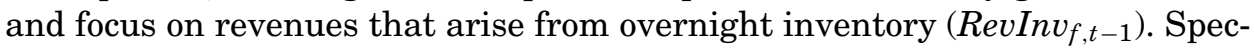
ification (2) shows that these inventory-related revenues continue to predict liquidity at the specialist firm level, with $t$-statistics above four. In economic terms, if a specialist firm experiences a one-standard deviation inventory revenue shortfall of $\$ 0.52$ million, the spread on that firm's stocks the next day is wider by an average of 1.26 basis points ( $\$ 0.52$ million $\times$ the slope coefficient of 2.164).

We look next at nonlinearities following extreme specialist losses. In specification (3) we add a kink to both RevInv and RevTr at the lower quartile point $\left(25^{\text {th }}\right.$ percentile). As in the market-level results, the biggest losses are associated with significantly wider spreads. The slope coefficient on RevInv is about $-2,034$ on a typical day and about $-4,324(=-2,034-2,289)$ in the left tail of the inventory revenues distribution. We also find that larger inventories today lead to wider spreads tomorrow. However, the relationship is not as statistically strong, with a $t$-statistic of 1.82 in specification (4).

Specification (6) is the kitchen-sink version. Right-hand side variables in-

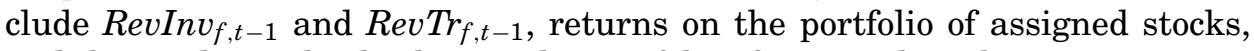
and the conditional volatility on the portfolio of assigned stocks:

$$
\begin{aligned}
\operatorname{Spr}_{f, t}= & \alpha+\beta_{1} \operatorname{RevInv}_{f, t-1}+\beta_{2} \operatorname{RevTr}_{f, t-1}+\beta_{3} \operatorname{Inv}_{f, t-1} \\
& +\beta_{4} \operatorname{Ret}_{f, t-1}+\beta_{5} \operatorname{varRet}_{f, t}+\varepsilon_{f, t} .
\end{aligned}
$$

Recall that all of these explanatory variables exhibit considerable covariation, so we expect some of them to become insignificant when all are included together. Revenues related to overnight inventory survive, but inventory does not fare well. When we add kinks to the revenue and inventory variables in specification (7), we find that the significant coefficient on RevInv is driven by the left tail of the distribution, again consistent with financial constraints binding more severely following relatively large revenue shortfalls. Overall, at the specialist firm level, there is evidence that specialist firm trading revenues and inventories affect next period's spreads.

Before we go on, it is worth giving some thought to the link between the specialist firm results and the market-level results in the previous section. Financing constraints operating at the specialist firm level need not imply strong effects at the market level. However, if there is a strong common factor in revenues and inventories across specialist firms, financing constraints would tend to bind for all specialist firms at once, and there would be a market-wide 
reduction in specialist liquidity provision. To investigate this, we calculate the contemporaneous correlation for both revenues and inventories for each possible pair of specialist firms. The average pairwise correlation of $R e v \operatorname{In} v_{f, t}$ is 0.215 , while the average pairwise correlation of $I n v_{f, t}$ is 0.110 . Thus, specialist firms tend to lose money at the same time, and they suffer similar inventory shocks.

Why are revenue and inventory measures positively correlated across specialist firms? Because there is a strong common factor in returns, and specialist firms tend to be net long most of the time. If the market is down, specialists across the floor are probably accumulating stock as part of their liquidity provision, leading to a positive correlation in absolute inventories. The variable $R e v I n v_{f, t}$ is positively correlated because most specialist firms are net long, so they all tend to lose money on these inventories when the market is down for the day. In short, broad market declines cause constraints to bind at most specialist firms at the same time, and the specialist-firm relation becomes a market-wide phenomenon.

Next, we identify and examine specialist firms that a priori are likely to face financing constraints. In Section V, we compare these firms to others that are less likely to face financing constraints. And in Section VI, we look at what happens when the more-constrained firms merge with deeper-pocketed partners.

\section{Evidence from Specialist Firm Ownership Structures}

If some specialist firms have less access to capital, there should be crosssectional differences in the sensitivity of spreads to inventories and trading losses. While we do not have access to the specialist firms' balance sheets or income statements, Coughenour and Deli (2002) identify three firms that are owned by the specialists themselves. The authors also identify three specialist firms in which the specialists are only employees (corporate ownership). Conversations with specialists suggest that specialist-owned firms may have less access to capital than corporate-owned specialist firms. In this section, we investigate whether there is a cross-sectional difference in how these two kinds of specialist firms react to trading losses and inventory shocks.

We construct a panel of daily data for these six specialist firms, beginning on January 1, 1994. Each specialist firm remains in the sample until it is acquired or March 1, 2002 (the date the last of the three specialist-owned firms is acquired), whichever is earlier. Variables are measured at the specialist firm level as in Section IV. We define an indicator variable Dum $_{f, t-1}$ that is equal to one for specialist-owned firms and zero otherwise. We then interact this dummy with all of the right-hand side variables. For example, a specification with only inventories on the right-hand side becomes

$$
\operatorname{Spr}_{f, t}=\alpha_{1}+\alpha_{2} \operatorname{Dum}_{f, t-1}+\beta_{1}\left|\operatorname{Inv}_{f, t-1}\right|+\beta_{2}\left|\operatorname{Inv}_{f, t-1}\right| \cdot \operatorname{Dum}_{f, t-1}+\varepsilon_{f, t} .
$$


Table V

\section{Specialist Firm Ownership Structure as a Proxy for Financing Constraints}

Data include the three specialist-owned firms and three corporate-owned specialist firms identified in Coughenour and Deli (2002). The panel of daily data starts January 1, 1994 and ends March 1, 2002. Regression variables are calculated using the stocks assigned to a given specialist firm denoted by $f$. The dependent variable is $\operatorname{Spr}(\%)_{f, t}$. Explanatory variables are interacted with a dummy (Dum) that is equal to 1 for specialist-owned firms and 0 otherwise. All coefficients are multiplied by $10^{3}$. $t$-statistics are in brackets and account for both time-series and cross-sectional correlation.

\begin{tabular}{|c|c|c|c|}
\hline & (1) & (2) & (3) \\
\hline \multirow[t]{2}{*}{ Intercept } & -31.52 & -162.80 & -9.29 \\
\hline & [2.47] & [2.96] & [0.29] \\
\hline \multirow[t]{2}{*}{ IntDum } & 2.45 & 45.27 & 3.08 \\
\hline & {$[0.69]$} & {$[0.82]$} & {$[0.09]$} \\
\hline \multirow[t]{2}{*}{$\operatorname{RevIn} v_{f, t-1}$} & -133.75 & & -45.18 \\
\hline & [2.59] & & [1.08] \\
\hline \multirow[t]{2}{*}{$\operatorname{RevInvDum}_{f, t-1}$} & -432.64 & & -29.61 \\
\hline & [3.67] & & [0.43] \\
\hline \multirow[t]{2}{*}{$\operatorname{Rev} \operatorname{Tr}_{f, t-1}$} & 13.22 & & -1.08 \\
\hline & {$[7.50]$} & & [0.62] \\
\hline \multirow[t]{2}{*}{$\operatorname{RevTrDum}_{f, t-1}$} & -5.44 & & 4.55 \\
\hline & {$[0.47]$} & & {$[0.45]$} \\
\hline \multirow[t]{2}{*}{$\operatorname{In} v_{f, t-1}$} & & 6.13 & 1.17 \\
\hline & & {$[3.81]$} & {$[1.19]$} \\
\hline \multirow[t]{2}{*}{$\operatorname{InvDum}_{f, t-1}$} & & 22.78 & 10.29 \\
\hline & & {$[2.36]$} & [3.58] \\
\hline \multirow[t]{2}{*}{$\operatorname{Ret}_{f, t-1}$} & & & -106.40 \\
\hline & & & [6.27] \\
\hline \multirow[t]{2}{*}{$\operatorname{RetDum}_{f, t-1}$} & & & -82.13 \\
\hline & & & [3.23] \\
\hline \multirow[t]{2}{*}{$\operatorname{var} \operatorname{Ret} f, t$} & & & 232.60 \\
\hline & & & [3.30] \\
\hline \multirow[t]{2}{*}{$\operatorname{varRetDum}_{f, t}$} & & & 137.02 \\
\hline & & & [1.98] \\
\hline Observations & 10,642 & 10,642 & 10,642 \\
\hline$R^{2}$ & 0.019 & 0.012 & 0.157 \\
\hline
\end{tabular}

In the above regression, we are interested in the null hypothesis that $\beta_{2}=0$. More generally, we look to all of the interaction terms for evidence that spreads of stocks assigned to specialist-owned firms are more sensitive to inventory and revenue shocks. Standard errors in these pooled regressions are based on Thompson (2009).

Table V presents the results. In each specification, we reject the null in favor of the alternative that spreads are more sensitive for specialist-owned firms. For example, specification (1) reveals that a $\$ 1$ million shock to inventory revenues causes a 0.134 basis point change in spreads for corporate-owned specialist firms. The effect is more than tripled for specialist-owned firms. Specification (2) in the table corresponds to equation (10), above, and uses only 
inventories as an explanatory variable. The effect of firm ownership structure is similarly strong, with a $t$-statistic of 2.36 on the interacted inventory variable. When we throw revenues, inventories, past stock returns, and conditional return variances into the regression together, the specialist revenue variables become insignificant, but the coefficient on the interacted inventory variable is 10.29 , with a $t$-statistic of 3.58. This means that an additional $\$ 1$ million of inventory is associated with an additional 0.010 basis points of spread for the specialist-owned firm relative to other specialist firms.

Thus, we have strong evidence that access to capital can affect the sensitivity of spreads to market-maker revenue and inventory shocks. However, it is possible that the stocks assigned to specialist-owned firms are somehow different from the stocks assigned to corporate-owned specialist firms, and that these assignments somehow account for our results in Table V. To address this possibility, we look next at a time-series analysis of the same stocks following a relaxation of financial constraints.

\section{Evidence from Specialist Firm Mergers}

In this section we ask: What happens if financing constraints are suddenly relaxed? Specialists should become less sensitive to losses and less constrained by large inventory positions. We investigate whether deep pockets help specialists provide liquidity by studying the mergers of the three specialist-owned firms from Section V. The first merger took place on March 20, 2001 when Benjamin Jacobson \& Sons was acquired by Spear Leeds Kellogg. On October 19, 2001, Bocklet \& Company was acquired by LaBranche \& Co. The final merger took place on March 1, 2002, with Van Der Moolen acquiring Lyden, Dolan, Nick \& Company.

The empirical strategy is straightforward. We first identify the set of stocks assigned to each target specialist firm just prior to the merger. The same stocks are studied post-merger to see if there is a change in the sensitivity of spreads to inventories and revenues. Specifically, we define a dummy variable Post $_{f, t-1}$ for each date and specialist firm that is equal to one after a firm is merged and zero otherwise. We interact this dummy with each of the included revenue and inventory measures to see if there is an identifiable difference in sensitivities post-merger. As in the previous section, the data are pooled. The regression specification with only inventories on the right-hand side is

$$
\operatorname{Spr}_{f, t}=\alpha_{1}+\alpha_{2} \operatorname{Post}_{f, t-1}+\beta_{1}\left|\operatorname{Inv}_{f, t-1}\right|+\beta_{2}\left|\operatorname{Inv}_{f, t-1}\right| \cdot \text { Post }_{f, t-1}+\varepsilon_{f, t},
$$

and the relevant null hypothesis is that $\beta_{2}=0$. The pre-merger period covers event days $[-70,-11]$, or about 3 calendar months. The post-merger period is defined symmetrically as event days $[+11,+70] .{ }^{16}$ We apply Newey-West standard errors with 10 lags to each pre-merger or post-merger period in order to account for time-series dependence in the regression errors.

\footnotetext{
${ }^{16}$ The results are not sensitive to the time interval chosen. The 3 -month interval ensures that none of the pre- and post-merger sample periods overlap across the three mergers.
} 


\section{Table VI}

\section{Mergers of Specialist Firms}

Panel regressions for the three specialist-owned firms identified in Coughenour and Deli (2002). We analyze liquidity before (event days -70 to -11 ) and after (event days +11 to +70 ) they merge with larger corporate-owned specialist firms. Regression variables are denoted $f$ and are calculated using the set of stocks assigned to the owner-specialist firm prior to the merger. The dependent variable is $\operatorname{Spr}(\%)_{f, t}$. Explanatory variables are interacted with a dummy (Post) equal to 1 after the merger is consummated and 0 before. All coefficients are scaled by $10^{3}$. Newey-West $t$-statistics with 10 lags are in brackets.

\begin{tabular}{|c|c|c|c|}
\hline & (1) & (2) & (3) \\
\hline Intercept & $\begin{array}{c}1.46 \\
{[0.01]}\end{array}$ & $\begin{array}{r}-474.29 \\
{[1.93]}\end{array}$ & $\begin{array}{r}-389.34 \\
{[2.83]}\end{array}$ \\
\hline IntPost & $\begin{array}{r}-186.14 \\
{[0.76]}\end{array}$ & $\begin{array}{r}300.94 \\
{[1.09]}\end{array}$ & $\begin{array}{r}233.23 \\
{[1.26]}\end{array}$ \\
\hline $\operatorname{RevInv}_{f, t-1}$ & $\begin{array}{r}-1,477.01 \\
{[1.45]}\end{array}$ & & $\begin{array}{r}441.14 \\
{[1.00]}\end{array}$ \\
\hline $\operatorname{RevInvPost}_{f, t-1}$ & $\begin{array}{r}1,337.99 \\
{[1.27]}\end{array}$ & & $\begin{array}{r}-446.13 \\
{[0.87]}\end{array}$ \\
\hline $\operatorname{Rev} \operatorname{Tr}_{f, t-1}$ & $\begin{array}{r}-371.87 \\
{[0.60]}\end{array}$ & & $\begin{array}{r}-581.55 \\
{[1.31]}\end{array}$ \\
\hline $\operatorname{RevTrPost}_{f, t-1}$ & $\begin{array}{r}-14.94 \\
{[0.02]}\end{array}$ & & $\begin{array}{r}539.89 \\
{[1.13]}\end{array}$ \\
\hline $\operatorname{In} v_{f, t-1}$ & & $\begin{array}{r}132.63 \\
{[1.52]}\end{array}$ & $\begin{array}{l}75.27 \\
{[1.89]}\end{array}$ \\
\hline InvPost $_{f, t-1}$ & & $\begin{array}{r}-145.01 \\
{[1.63]}\end{array}$ & $\begin{array}{r}-80.68 \\
{[1.75]}\end{array}$ \\
\hline $\operatorname{Ret}_{f, t-1}$ & & & $\begin{array}{r}-164.69 \\
{[2.40]}\end{array}$ \\
\hline $\operatorname{RetPost}_{f, t-1}$ & & & $\begin{array}{r}193.95 \\
{[2.41]}\end{array}$ \\
\hline $\operatorname{varRet}_{f, t}$ & & & $\begin{array}{r}578.82 \\
{[4.40]}\end{array}$ \\
\hline $\operatorname{varRetPost}_{f, t}$ & & & $\begin{array}{r}203.06 \\
{[0.61]}\end{array}$ \\
\hline Observations & 360 & 360 & 360 \\
\hline$R^{2}$ & 0.052 & 0.040 & 0.439 \\
\hline
\end{tabular}

The results are in Table VI. In every case, we find that the coefficient estimates are consistent with the financial constraints hypothesis, though we do not obtain statistical significance. The lack of significance is perhaps due to a lack of power given the presence of only three specialist-owned firms in the sample. For the set of stocks previously assigned to the specialist-owned firm, spreads become less sensitive to both revenues and inventories post-merger. Consider specification (2), for example. The pre-merger sensitivity to specialist firm level inventories is 132.63 , which means that a $\$ 1$ million increase in inventories increases effective spreads by an average of 0.133 basis points, while the post-merger sensitivity to absolute inventories is actually slightly negative (132.63 - 145.01) and statistically indistinguishable from zero. This suggests that the deep pockets of the acquiring firm enable these specialists 
to take on inventory without widening the spread. The results for specialist revenues in specifications (1) and (3) have the correct signs, but again the results are not statistically significant. For example, the $t$-statistic is 1.27 on the RevInvPost $_{f, t}$ interaction term in specification (1). Overall, the evidence points to improvements in the specialist's ability to commit capital to liquidity provision once these specialist-owned firms are taken over, but the findings are not statistically strong.

\section{Flight to Quality: The Role of Inventories and Revenues}

The Brunnermeier and Pedersen (2009, p. 2206) model implies that "risky securities become especially illiquid ... when [available dealer] capital deteriorates, which induces them to mostly provide liquidity in securities that do not use much capital (low-volatility stocks with lower margins), implying that the liquidity differential between high-volatility and low-volatility securities increases." They term this effect "flight to quality" because the liquidity of low volatility (high quality) securities is relatively less sensitive to inventory shocks. In our paper, both inventories and specialist revenue measures identify reductions in available dealer capital, and these variables can be used to test flight-to-quality predictions.

Because fundamental volatility is unobservable, we sort stocks into quartiles using their realized volatility. Each day we calculate each stock's rolling 60-day return volatility, lagged 10 days (i.e., using returns from days $t-11$ to $t-70$ ). We then sort the stocks based on this rolling volatility. For the lowest and highest quartiles, we calculate an aggregate market-wide proportional effective spread measure for day $t$ using the same quasi-differencing, demeaning, and aggregation methodology described in Section II. The new measures are denoted $\mathrm{Spr}_{t}^{\mathrm{Lo \sigma}}$ and $\mathrm{Spr}_{t}^{\mathrm{Hi \sigma} \text {. }}$

To test whether there is evidence of a flight to quality in liquidity provision, we regress the spreads of the lowest and highest volatility quartiles on absolute inventories and the two components of aggregate specialist trading revenues,

$$
\begin{aligned}
& \operatorname{Spr}_{m, t}^{L o \sigma}=\alpha_{L}+\beta_{1}^{L}\left|\operatorname{Inv}_{m, t-1}\right|+\beta_{2}^{L} \operatorname{RevInv}_{m, t-1}+\beta_{3}^{L} \operatorname{RevTr}_{m, t-1}+\varepsilon_{m t}^{L} \\
& \operatorname{Spr}_{m, t}^{H i \sigma}=\alpha_{H}+\beta_{1}^{H}\left|\operatorname{Inv}_{m, t-1}\right|+\beta_{2}^{H} \operatorname{RevInv}_{m, t-1}+\beta_{3}^{H} \operatorname{Rev}_{\operatorname{Tr}_{m, t-1}}+\varepsilon_{m t}^{H},
\end{aligned}
$$

and test the null hypothesis $\beta_{1}^{H}=\beta_{1}^{L}$ or $\beta_{2}^{H}=\beta_{2}^{L}$ against the alternative that the sensitivities are different in the two volatility quartiles. To conduct the statistical test, we subtract the second equation in (12) from the first, regress the cross-sectional difference in spreads on the inventory and revenue variables, and test whether the relevant slope coefficients are different from zero.

In addition to this specification, we estimate versions of equation (12) using subsets and supersets of these variables, as well as piecewise linear versions. The results for stocks in the low volatility quartile are in Table VII, Panel $\mathrm{A}$, and the results for stocks in the high volatility quartile are in Table VII, Panel B. In specification (2), which includes only the trading revenue 


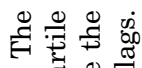

ㄷㅀ

1

o:

$\therefore \frac{\pi}{0} \frac{\pi}{0}$

$1+0$

on 0

ฮำ

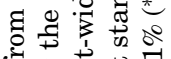

के

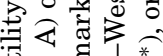

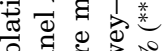

है कै

o क

․ㅠㄹ

$\infty$

긍

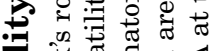

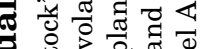

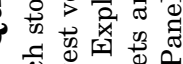

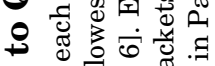

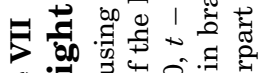

存

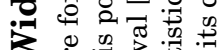

के

0

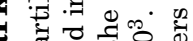

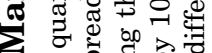

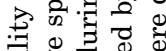
$\Rightarrow$

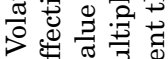

政

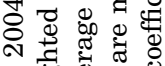

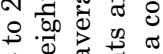

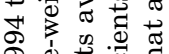

今.

졍

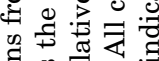

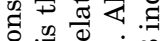

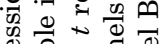

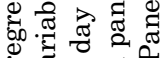

$\rightarrow=$ व

पै

过

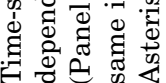

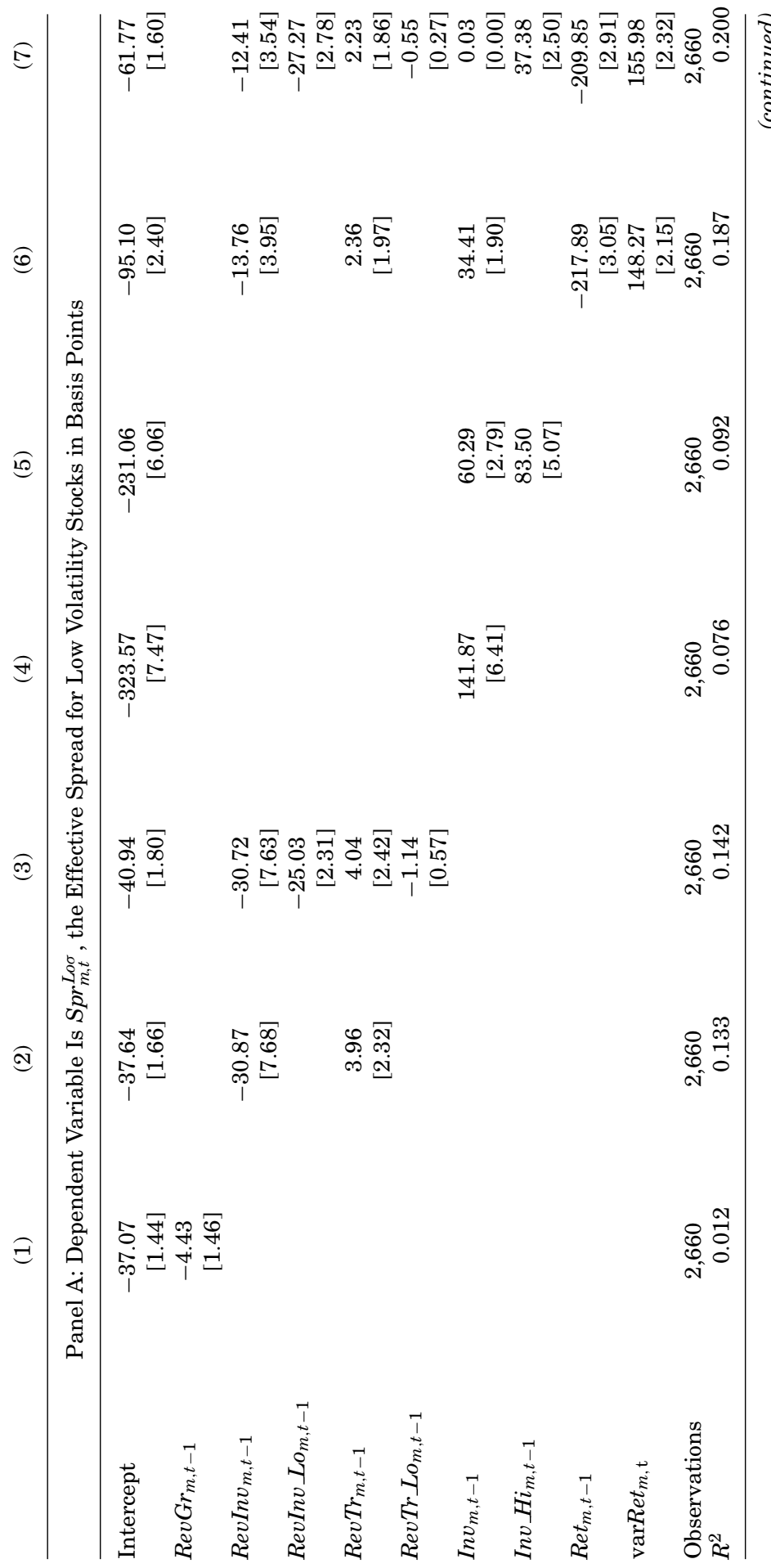


Time Variation in Liquidity

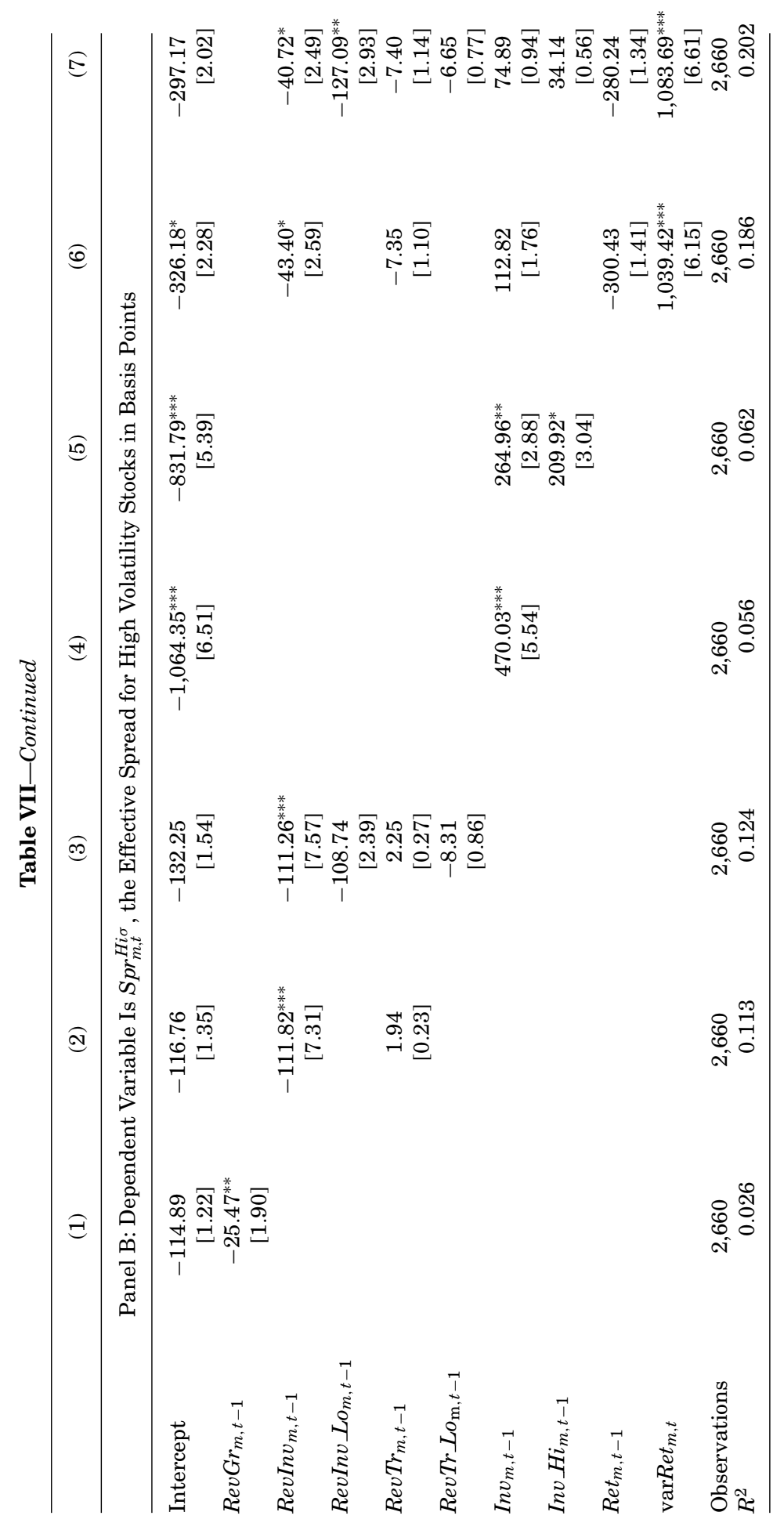


variables, the coefficient on $\operatorname{RevInv}_{m, t-1}$ is significant and negative for both low volatility stocks (Panel A) and high volatility stocks (Panel B), and the coefficient on $\operatorname{RevInv_{m,t-1}}$ is more than three times as negative for high volatility stocks, consistent with the flight-to-quality prediction. The asterisks in Panel B indicate that this cross-sectional difference is strongly statistically significant. In fact, the $t$-statistic is almost 6 . The piecewise linear version in specification (3) shows large liquidity effects for high volatility stocks when RevInv $v_{m, t-1}$ is below its $25^{\text {th }}$ percentile. Specification (4) uses absolute inventories alone and yields slope coefficients of 141.87 for low volatility stocks in Panel A and 470.03 for high volatility stocks in Panel B; $t$-statistics are 6.41 and 5.54, respectively. In other words, if aggregate absolute inventories are $\$ 100$ million greater, the quasi-differenced spread measure on high volatility stocks exceeds the spread measure on low volatility stocks by an average of 0.328 basis points, suggesting that market makers are concentrating their limited risk-bearing capacity in the most liquid stocks. Specification (5) shows that inventory effects are also nonlinear; the flight-to-quality effect is somewhat larger when absolute aggregate inventory is above its $75^{\text {th }}$ percentile value. Finally, specifications (6) and (7) show that when all the specialist variables are included in the same regression along with market returns and conditional volatility, the coefficients on revenues and inventories are larger for high volatility stocks than for low volatility stocks, consistent with a flight-to-quality effect. Note that the difference in the inventory revenue coefficients is statistically significant while the difference in the inventory coefficients is not.

The same kind of flight to quality should also be apparent at the specialist firm level. We replace market-wide variables with specialist firm-level absolute inventories and revenue variables, and we sort each specialist firm's assigned stocks into quartiles based on realized volatility. Each day we calculate the average proportional effective spread for the lowest and highest volatility quartiles, ${ }^{17}$ regress spread measures on specialist firm-level inventories and revenue measures, and test the null that the relevant pair of coefficients is the same for low volatility and high volatility stocks. ${ }^{18}$

The results are in Table VIII and are qualitatively similar to the marketwide results from Table VII. In specifications (2) and (3), the coefficient on

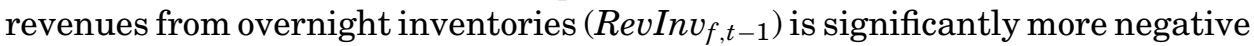
for high volatility stocks. In specifications (4) and (5), high volatility spreads are marginally more sensitive to inventory levels. When lagged market returns and conditional variances are added in specifications (6) and (7), the difference in the inventory revenue coefficients remains marginally significant, but the

\footnotetext{
${ }^{17}$ At the specialist firm level, spreads are quite noisy for stocks in the high volatility quartile. Therefore, we winsorize the spread data series at the $1 \%$ and $99 \%$ levels to control for extreme values.

${ }^{18} \mathrm{As}$ in the earlier analysis at the specialist firm level (Table IV), we estimate time-series regressions separately for each specialist firm because of potential specialist firm heterogeneity. We report average coefficient estimates and estimate standard errors that are robust to both crosssectional correlation across specialist firms and time-series persistence within specialist firms (see Appendix B for details).
} 


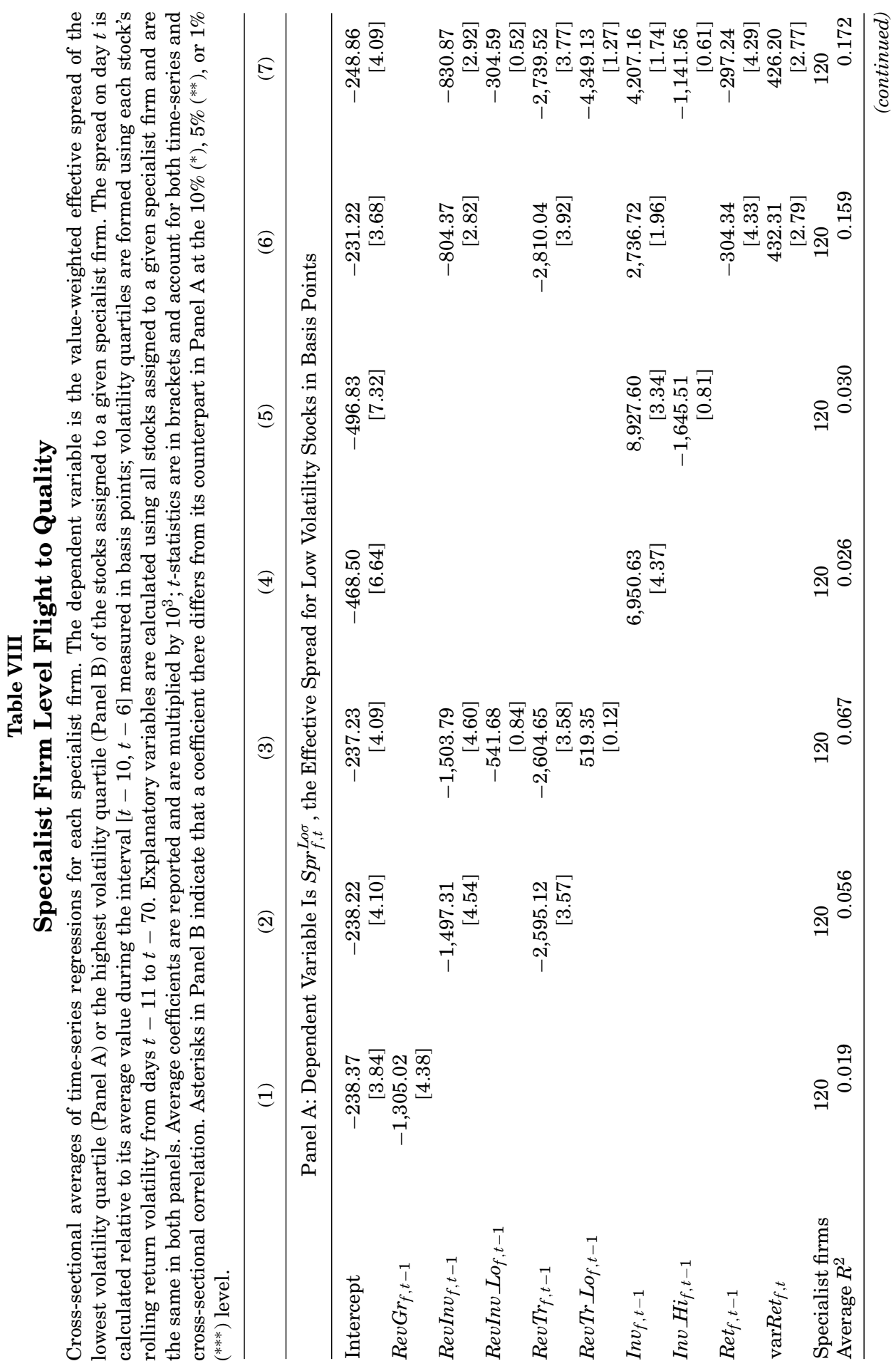




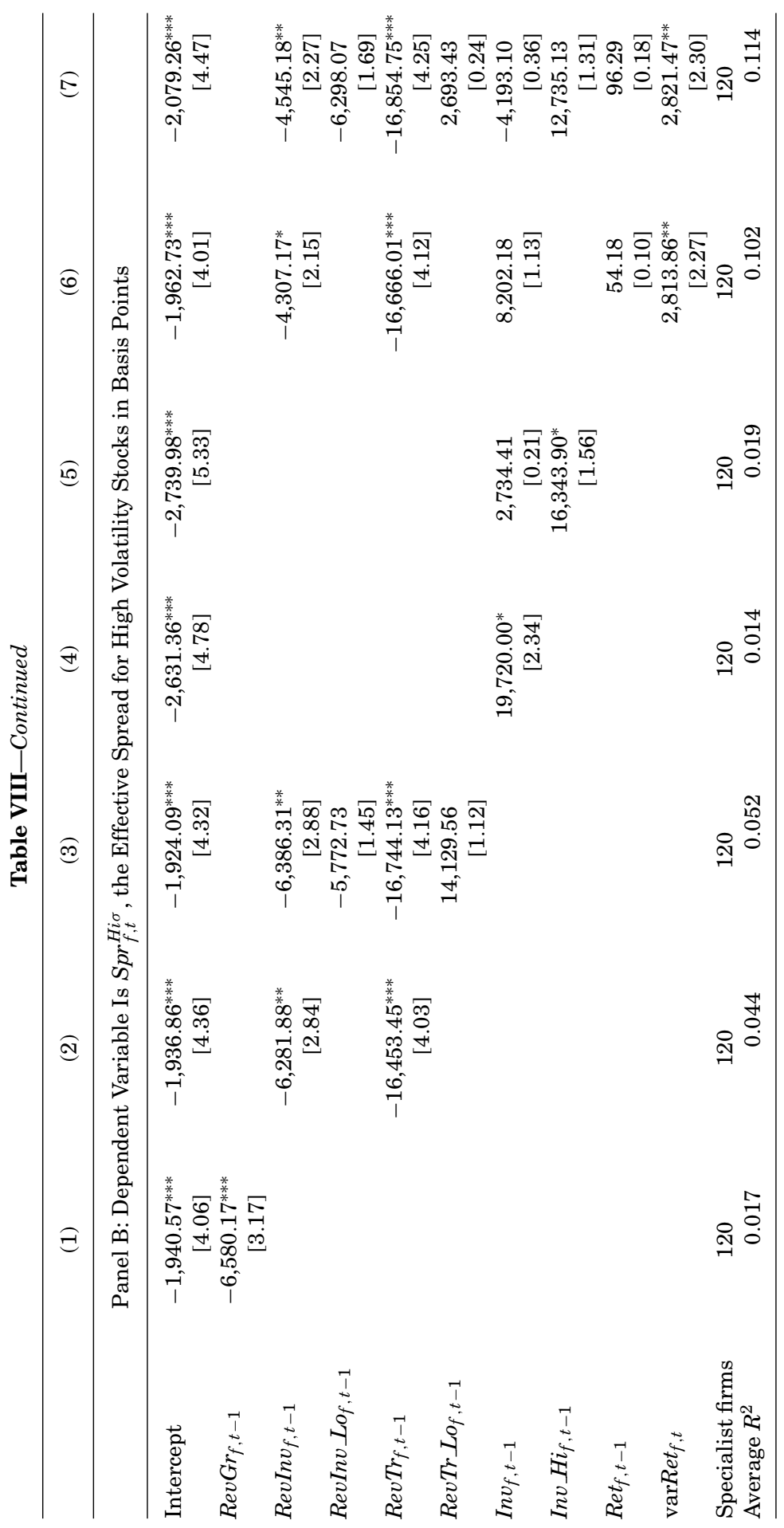


difference in the inventory coefficients does not. Overall, the evidence at both the market level and the specialist firm level is consistent with the flight-toquality story.

\section{Conclusions}

In this paper, we use an 11-year panel of daily specialist inventories and revenues on individual NYSE stocks to explore the relations between liquidity and market-maker financial variables. At both the aggregate level and the specialist firm level, we show that when specialists find themselves with larger positions or lose money on their inventories, effective spreads are significantly wider in the days that follow. When we include inventories, inventory-related specialist revenues, market returns, and conditional return volatility at the aggregate market level, we find that inventories, revenues, and volatility have incremental predictive power for future liquidity. This suggests that marketmaker financial constraints can help us understand time variation in liquidity, while also acknowledging the traditional mechanisms of microstructure theory that link price volatility and liquidity.

NYSE specialists are the most important liquidity suppliers of NYSE-listed stocks, given the structural advantages that accrue to specialists over our sample period. Thus, studying the inventories and revenues of specialists is ideal for starting to understand time-varying liquidity in the world's largest stock market. Clearly, there are other competing liquidity suppliers, such as market makers on regional exchanges, proprietary trading desks at various Wall Street firms, and hedge funds following a market-making strategy. Information about their financial condition and trading behavior would be of considerable interest. But if all liquidity suppliers follow similar strategies and suffer similar shocks (Boehmer and Wu (2008) provide some suggestive evidence along these lines), our data may be proxying for this much broader market-making sector.

Ultimately, our revenue and inventory measures are somewhat noisy proxies for the presence of financial constraints. It would be useful to obtain direct evidence on changes in collateral requirements, credit limits, or financing costs imposed by lenders in response to trading losses. Unfortunately, such data are not readily available to us. However, Coughenour and Deli (2002) identify three specialist firms that are owned by the specialists themselves, along with three corporate-owned specialist firms in which the specialists are employees. Specialist-owned firms may have less access to capital than corporate-owned specialist firms. We find that the sensitivity of liquidity to inventories and revenues is greater for specialist-owned firms compared to corporate-owned specialist firms. The sensitivity is also reduced when specialist-owned firms merge with corporate-owned firms, consistent with deep pockets easing financing constraints.

While we use specialist data from the NYSE, it is important to emphasize that our results are about market-making, not NYSE specialists per se. Our results should generalize to other market structures. For example, specialists have become much less important since the NYSE adopted its mostly 
electronic "Hybrid" market structure in 2007. But other liquidity suppliers (such as quantitative hedge funds) have taken the specialists' place, and these liquidity suppliers face exactly the same kinds of financing constraints. In fact, given the U.S. credit crunch of 2007 to 2008, financing constraints are probably quite severe at the moment, and if the data were available (unfortunately a big if), it would be extremely interesting to see how shocks to the new liquidity suppliers are affecting stock market liquidity.

Our results also have implications for theoretical work. Liquidity is a nebulous concept, and there is necessarily some distance between liquidity in the current theoretical models of financing constraints and our empirical measures. For example, most of the theoretical models do not attempt to capture the continuous nature of trading and instead employ Walrasian auctions that are not fully dynamic and have no explicit bid-ask spread. In that sense, our findings move ahead of existing theory, and developing an explicit dynamic inventory management problem in the face of financing constraints could be a promising avenue for future research.

Finally, our results have potential policy implications. Because liquidity is a public good with positive externalities for all traders-Gromb and Vayanos (2002) and Weill (2007)-financial constraints can lead to an undersupply of liquidity. If too little capital is available for market making, there are several possible solutions. First, regulators could raise capital requirements for liquidity suppliers such as specialists. This may be beneficial in avoiding liquidity meltdowns, but could also raise the costs of liquidity suppliers' day-to-day operations (e.g., opportunity costs of underutilized capital). Thus, higher capital requirements might make supplying liquidity less attractive, potentially driving out existing market makers and/or reducing new entry. Second, there could be subsidies for liquidity suppliers through reduced trading fees, direct payment for trading (e.g., liquidity rebates for non-marketable limit orders), or an advantageous position in the trading environment. Special privileges for market makers have been the traditional mechanism to encourage liquidity provision, but such advantages are open to abuse, as seen by the odd-eighths and specialist scandals on NASDAQ and the NYSE. Third, predation of liquidity suppliers should be discouraged, especially when liquidity suppliers have taken large capital positions or lost money. Measuring and defining predation would undoubtedly prove challenging, intrusive, and contentious. Finally, a liquidity supplier of last resort may be valuable when existing liquidity suppliers have committed most of their capital. For example, the Fed's actions to provide liquidity in 1987 may have prevented a crisis-see SEC (1988). However, having a liquidity supplier of last resort can cause moral hazard problems in the form of excess risk-taking. To prevent such behavior, regulators could designate liquidity suppliers and track their positions and trading closely. In exchange for being monitored, market makers could receive more favorable lending terms from the Fed (especially during times of low liquidity). In fact, the recent extension of Federal Reserve liquidity facilities to investment banks is exactly a step in this direction, as is SEC chairman Christopher Cox's recent call for investment banks to disclose publicly more details about capital and 
liquidity positions. ${ }^{19}$ These moves could have the beneficial effect of reducing the variability of liquidity and its sensitivity to various shocks.

\section{Appendix A: Specialist Trading Revenues}

For each stock and each day, we measure the specialist's gross revenues from trading. The gross revenues do not subtract costs such as salaries, fees, or technology investments, nor do they include possible sources of revenues such as brokerage commissions charged to other floor participants. The gross trading revenues (GTR) of stock $i$ on day $t$ are calculated as in Sofianos (1995) by marking to market the specialist's starting and ending inventories and adding the gross profits due to buying and selling:

$$
G T R_{i t}=\left(S_{i t}-B_{i t}\right)+\left(p_{i t} I_{i t}-p_{i, t-1} I_{i, t-1}\right),
$$

where $p_{i, t}$ is the share price of stock $i$ at the end of day $t, I_{i, t}$ is the specialist's inventory in shares of stock $i$ at the end of day $t, S_{i, t}$ is the total dollar value of stock $i$ sold on day $t$, and $B_{i, t}$ is the total dollar value of shares bought. For simplicity we suppress subscripts $i$ in the discussion that follows.

To further decompose the gross revenues, we define $\bar{p}_{t}^{s}$ to be the specialist's average selling price on day $t, \bar{p}_{t}^{b}$ to be the corresponding average buying price, $s_{t}$ to be the shares sold on day $t$, and $b_{t}$ to be the shares bought on day $t$. Thus, $S_{t}=s_{t} \bar{p}_{t}^{s}$ and $B_{t}=b_{t} \bar{p}_{t}^{b}$ which allows us to re-write gross trading revenue:

$$
G T R_{t}=\left(s_{t} \bar{p}_{t}^{s}-b_{t} \bar{p}_{t}^{b}\right)+p_{t}\left(I_{t}-I_{t-1}\right)+I_{t-1}\left(p_{t}-p_{t-1}\right) .
$$

We then expand the first term in parentheses to get

$$
\begin{aligned}
G T R_{t}= & \min \left(s_{t}, b_{t}\right)\left(\bar{p}_{t}^{s}-\bar{p}_{t}^{b}\right)+\bar{p}_{t}^{s}\left(s_{t}-b_{t}\right)^{+}-\bar{p}_{t}^{b}\left(b_{t}-s_{t}\right)^{+} \\
& +p_{t}\left(I_{t}-I_{t-1}\right)+I_{t-1}\left(p_{t}-p_{t-1}\right),
\end{aligned}
$$

where $(x)^{+} \equiv \max (x, 0)$. Finally, using the fact that $I_{t}=I_{t-1}+\left(b_{t}-s_{t}\right)$, we obtain

$$
\begin{aligned}
G T R_{t}= & \min \left(s_{t}, b_{t}\right)\left(\bar{p}_{t}^{s}-\bar{p}_{t}^{b}\right)+\left(p_{t}-\bar{p}_{t}^{b}\right)\left(b_{t}-s_{t}\right)^{+} \\
& +\left(\bar{p}_{t}^{s}-p_{t}\right)\left(s_{t}-b_{t}\right)^{+}+I_{t-1}\left(p_{t}-p_{t-1}\right) .
\end{aligned}
$$

The first term of this equation captures the difference in buying and selling prices for all round-trip transactions that the specialist completes on day $t$, and we call this round-trip trading revenue $R T R_{t}$ :

$$
R T R_{t}=\min \left(s_{t}, b_{t}\right)\left(\bar{p}_{t}^{s}-\bar{p}_{t}^{b}\right) .
$$

The remaining terms are defined as inventory-related trading revenue $I T R_{t}$ :

$$
I T R_{t}=\left(p_{t}-\bar{p}_{t}^{b}\right)\left(b_{t}-s_{t}\right)^{+}+\left(\bar{p}_{t}^{s}-p_{t}\right)\left(s_{t}-b_{t}\right)^{+}+I_{t-1}\left(p_{t}-p_{t-1}\right) .
$$

${ }^{19}$ Chung, Joanna, and Ben White, 2008, SEC to require banks to disclose liquidity, Financial Times, May 7, http://www.ft.com/cms/s/0/48034c9e-1c83-11dd-8bfc-000077b07658. html?nclick_check=1; text of speech at http://www.sec.gov/news/speech/2008/spch050708cc.htm. 
The first two terms of ITR reflect the mark-to-market profits on day $t$ 's changes in inventory (either long or short), and the last term is the mark-tomarket profit on the starting inventory position. The term ITR can be thought of as revenues from inventories held overnight. To be precise, ITR measures revenues from the close of day $t-1$ to the close of day $t$ on positions that are held at the close on day $t-1$ or at the close on day $t$. Note also that ITR incorporates both overnight price changes (on day $t-1$ inventory) and price changes during day $t$. Thus, we have decomposed daily specialist profits for each stock into two parts reflecting an intraday spread-related component and a component related to multi-day inventory:

$$
G T R_{t}=R T R_{t}+I T R_{t}
$$

To calculate aggregate-level (subscript $m$ ) or specialist firm-level (subscript $f$ ) market-maker revenues for each day, GTR, RTR, and ITR are summed across all relevant stocks. Specialist participation rates and the nature of specialist trading change markedly when the minimum tick size changes from eighths to sixteenths on June 24, 1997 and from sixteenths to pennies on January $29,2001 .^{20}$ Specialist participation also changes markedly at the beginning of 2003. To adjust for these discontinuities, we calculate the time-series mean of daily specialist revenues in each of four regimes-one for each minimum tick, plus an additional breakpoint at January 1, 2003-and adjust our aggregate revenue measures by the appropriate regime mean.

In the regressions, we aggregate revenues over 5 days. The variables used in regressions and discussed in the body of the paper are thus

$$
\begin{aligned}
& \operatorname{Rev} \mathrm{r}_{m, t}=\sum_{j=0}^{4} G T R_{m, t-j} \\
& \operatorname{RevInv_{m,t}}=\sum_{j=0}^{4} I T R_{m, t-j} \\
& \operatorname{RevTr} r_{m, t}=\sum_{j=0}^{4} R T R_{m, t-j}
\end{aligned}
$$

for market-wide measures, and similarly for specialist firm-level revenue measures, subscripted $f$.

\section{Appendix B: Standard Error Calculations for Heterogeneous Panel Regressions}

For specialist firm $i$, we have $T_{i}$ time-series observations and a linear relation:

$$
y_{i}=X_{i} \beta_{i}+\varepsilon_{i},
$$

\footnotetext{
${ }^{20}$ The NYSE moved approximately 100 common stocks to decimals between September and December 2000 as part of testing and roll-out plans. However, the vast majority of stocks switched on January 29, 2001.
} 
where $E\left(\varepsilon_{i}\right)=0, E\left(\varepsilon_{i} \varepsilon_{\mathrm{i}}^{\prime}\right)=\Omega_{i i}$, and $E\left(\varepsilon_{i t} \varepsilon_{i s}\right)=0$ for all $|t-s|>L$. The panel is unbalanced, and there may or may not be a time-series overlap for a given crosssectional pair $\{i, j\}$. We are interested in the distribution of the cross-sectional average OLS slope vector $\hat{\bar{\beta}}=\frac{1}{N} \sum \hat{\beta}_{i}$, where $N$ is the number of specialist firms. We allow for cross-sectional correlation, so the variance-covariance matrix of the average OLS slope vector depends on the pairwise covariances and is given by

$$
E\left((\hat{\bar{\beta}}-\bar{\beta})(\hat{\bar{\beta}}-\bar{\beta})^{\prime}\right)=\frac{1}{N^{2}} \sum_{i, j} E\left[\left(\hat{\beta}_{i}-\beta_{i}\right)\left(\hat{\beta}_{j}-\beta_{j}\right)^{\prime}\right] .
$$

Using the fact that $\hat{\beta}_{i}=\beta_{i}+\left(X_{i}^{\prime} X_{i}\right)^{-1} X_{i}^{\prime} \varepsilon_{i}$, we have

$$
E\left[\left(\hat{\beta}_{i}-\beta_{i}\right)\left(\hat{\beta}_{j}-\beta_{j}\right)^{\prime}\right]=E\left[\left(X_{i}^{\prime} X_{i}\right)^{-1} X_{i}^{\prime} \varepsilon_{i} \varepsilon_{j}^{\prime} X_{j}\left(X_{j}^{\prime} X_{j}\right)^{-1}\right]=H_{i}^{-1} G_{i j} H_{j}^{-1},
$$

where

$$
H_{i}^{-1}=\left(X_{i}^{\prime} X_{i}\right)^{-1}, G_{i j}=E\left[X_{i}^{\prime} \varepsilon_{i} \varepsilon^{\prime}{ }_{j} X_{j}\right]
$$

When $i=j$, and given the assumptions on $\Omega_{i i}$, we can get consistent estimates of $G_{i i}$ and thus $\operatorname{var}\left(\hat{\beta}_{\mathrm{i}}\right)$ using Newey-West with $L$ lags. We proceed analogously with the covariance terms. We assume a similar structure here, namely that $E\left(\varepsilon_{i} \varepsilon_{\mathrm{j}}^{\prime}\right)=\Omega_{i j}$, where $E\left(\varepsilon_{i t} \varepsilon_{j s}\right)=0$ for all $|t-s|>L$. Then $G_{i j}$ can be consistently estimated with the following analog to the Newey-West estimator:

$$
\hat{G}_{i j}=\sum_{t} e_{i t} e_{j t} x_{i t} x_{j t}^{\prime}+\sum_{k=1}^{L} \sum_{t=k+1}^{T} w_{k} e_{i t} e_{j, t-k}\left(x_{i t} x_{j, t-k}^{\prime}+x_{i, t-k} x_{j t}^{\prime}\right),
$$

where $w_{k}=1-\frac{k}{L+1}$ and $x_{i t}$ is a $k \times 1$ vector corresponding to the observation for firm $i$ at time $t$ (that is, $x_{i t}^{\prime}$ is the $t^{\text {th }}$ row of $X_{i}$ ).

The first term captures contemporaneous correlation between firm $i$ and $j$, and the double sum captures all of the cross-autocovariances between firm $i$ and firm $j$ up to the maximum lag $L$. Note that the summations extend over the entire sample. In the case of partial overlap, only those terms where both the $e_{i}$ and $e_{j}$ elements are non-missing should contribute to the overall sum. In particular, this implies that $G_{i j}=0$ when the gap between the firm $i$ observations and the firm $j$ observations is at least $L$ periods.

\section{REFERENCES}

Adrian, Tobias, and Hyun Song Shin, 2007, Liquidity, monetary policy and financial cycles, Current Issues in Economics and Finance 14, 1-7.

Amihud, Yakov, and Haim Mendelson, 1980, Dealership market: Market making with inventory, Journal of Financial Economics 8, 31-53.

Attari, Mukarram, Antonio Mello, and Martin Ruckes, 2005, Arbitraging arbitrageurs, Journal of Finance 60, 2471-2511. 
Bessembinder, Hendrik, 2003, Issues in assessing trade execution costs, Journal of Financial Markets 6, 233-257.

Boehmer, Ekkehart, and Julie Wu, 2008, Order flow and prices, Working paper, Texas A\&M University.

Brunnermeier, Markus, and Lasse H. Pedersen, 2005, Predatory trading, Journal of Finance 60, 1825-1863.

Brunnermeier, Markus, and Lasse H. Pedersen, 2009, Market liquidity and funding liquidity, Review of Financial Studies 22, 2201-2238.

Campbell, John, 1991, A variance decomposition for stock returns, Economic Journal 101, 157179.

Cao, Henry, Martin Evans, and Richard Lyons, 2006, Inventory information, Journal of Business 79, 325-363.

Chordia, Tarun, Richard Roll, and Avanidhar Subrahmanyam, 2000, Commonality in liquidity, Journal of Financial Economics 56, 3-28.

Chordia, Tarun, Richard Roll, and Avanidhar Subrahmanyam, 2001, Market liquidity and trading activity, Journal of Finance 56, 501-530.

Chordia, Tarun, Asani Sarkar, and Avanidhar Subrahmanyam, 2005, An empirical analysis of stock and bond market liquidity, Review of Financial Studies 18, 85-129.

Corwin, Shane, 2004, Specialist performance and new listing allocations on the NYSE: An empirical examination, Journal of Financial Markets 7, 27-51.

Coughenour, Jay, and Dan Deli, 2002, Liquidity provision and the organizational form of NYSE specialist firms, Journal of Finance 57, 841-869.

Coughenour, Jay, and Lawrence Harris, 2004, Specialist profits and the minimum price increment, Working paper, University of Delaware.

Coughenour, Jay, and Mohsen Saad, 2004, Common market makers and commonality in liquidity, Journal of Financial Economics 73, 37-69.

Garleanu, Nicolae, Lasse H. Pedersen, and Allen M. Poteshman, 2009, Demand-based option pricing, Review of Financial Studies 22, 4259-4299.

Glosten, Lawrence, Ravi Jaganathan, and David Runkle, 1993, On the relation between the expected value and the volatility of the nominal excess return on stocks, Journal of Finance 48, 1779-1801.

Glosten, Lawrence, and Paul Milgrom, 1985, Bid, ask and transaction prices in a specialist market with heterogeneously informed traders, Journal of Financial Economics 14, 71-100.

Gromb, Denis, and Dimitri Vayanos, 2002, Equilibrium and welfare in markets with financially constrained arbitrageurs, Journal of Financial Economics 66, 361-407.

Grossman, Sanford, and Merton Miller, 1988, Liquidity and market structure, Journal of Finance 43, 617-633.

Hameed, Allaudeen, Wenjin Kang, and S. Viswanathan, 2010, Stock market declines and liquidity, Journal of Finance 65, 257-294.

Hansch, Oliver, Nayaran Naik, and S. Viswanathan, 1999, Best execution, internalization, preferencing and dealer profits, Journal of Finance 54, 1799-1828.

Hasbrouck, Joel, and Duane Seppi, 2001, Common factors in prices, order flows and liquidity, Journal of Financial Economics 59, 383-411.

Hasbrouck, Joel, and George Sofianos, 1993, The trades of market-makers: An analysis of NYSE specialists, Journal of Finance 48, 1565-1594.

Hatch, Brian, and Shane Johnson, 2002, The impact of specialist firm acquisitions on market quality, Journal of Financial Economics 66, 139-167.

Hendershott, Terrence, and Mark S. Seasholes, 2007, Market maker inventories and stock prices, American Economic Review 97, 210-214.

Ho, Thomas, and Hans Stoll, 1981, Optimal dealer pricing under transactions and return uncertainty, Journal of Financial Economics 9, 47-73.

Ho, Thomas, and Hans Stoll, 1983, The dynamics of dealer markets under competition, Journal of Finance 38, 1053-1074.

Huberman, Gur, and Dominika Halka, 2001, Systematic liquidity, Journal of Financial Research $24,161-178$. 
Ip, Greg, and Susanne Craig, 2003, Trading cases: NYSE's “specialist” probe puts precious asset at risk, Wall Street Journal, April 18, 2003, A1.

Jones, Charles, 2006, A century of stock market liquidity and trading costs, Working paper, Columbia University.

Kavajecz, Kenneth A., and Elizabeth R. Odders-White, 2001, An examination of changes in specialists' posted price schedules, Review of Financial Studies 14, 681-704.

Kyle, Albert, 1985, Continuous auctions and insider trading, Econometrica 53, 1315-1336.

Kyle, Albert, and Wei Xiong, 2001, Contagion as a wealth effect, Journal of Finance 56, 1401-1440.

Lee, Charles, and Mark Ready, 1991, Inferring trade direction from intraday data, Journal of Finance 46, 733-747.

Lyons, Richard K., 2001, The Microstructure Approach to Exchange Rates (MIT Press, Cambridge, MA).

Madhavan, Ananth, and Seymour Smidt, 1993, An analysis of daily changes in specialist inventories and quotations, Journal of Finance 48, 1595-1628.

Madhavan, Ananth, and George Sofianos, 1998, An empirical analysis of NYSE specialist trading, Journal of Financial Economics 48, 189-210.

Manaster, Steven, and Steven Mann, 1996, Life in the pits: Competitive market making and inventory control, Review of Financial Studies 9, 953-975.

Mildenstein, Eckart, and Harold Schleef, 1983, The optimal pricing policy of a monopolistic market maker in the equity market, Journal of Finance 38, 218-231.

Mitchell, Mark, Lasse H. Pedersen, and Todd Pulvino, 2007, Slow moving capital, American Economic Review 97, 215-220.

Naik, Narayan, and Pradeep Yadav, 2003a, Do dealer firms manage inventory on a stock-by-stock or a portfolio basis? Journal of Financial Economics 69, 325-353.

Naik, Narayan, and Pradeep Yadav, 2003b, Risk management with derivatives by dealers and market quality in government bond markets, Journal of Finance 58, 1873-1904.

O'Hara, Maureen, and George S. Oldfield, 1986, The microeconomics of market making, Journal of Financial and Quantitative Analysis 21, 361-376.

Panayides, Marios, 2007, Affirmative obligations and market making with inventory, Journal of Financial Economics 86, 513-542.

Pástor, Luboš, and Robert Stambaugh, 2003, Liquidity risk and expected stock returns, Journal of Political Economy 111, 642-685.

Reiss, Peter, and Ingrid Werner, 1998, Does risk sharing motivate inter-dealer trading? Journal of Finance 53, 1657-1704.

Securities and Exchange Commission, 1988, The October 1987 market break, Division of Market Regulation report.

Shen, Pu, and Ross Starr, 2002, Market-makers' supply and pricing of financial market liquidity, Economics Letters 76, 53-58.

Sofianos, George, 1995, Specialist gross trading revenues at the New York Stock Exchange, NYSE Working Paper \#95-01.

Stoll, Hans, 1978, The supply of dealer services in security markets, Journal of Finance 33, 1133-1151.

Thompson, Samuel, 2009, Simple formulas for standard errors that cluster by both firm and time, Working paper, SSRN.

Weill, Pierre-Olivier, 2007, Leaning against the wind, Review of Economic Studies 74, 1329-1354.

Yuan, Kathy, 2005, Asymmetric price movements and borrowing constraints: A rational expectations equilibrium model of crises, contagion, and confusion, Journal of Finance 60, 379-411. 